ISSN: 0514-7336

DOI: http://dx.doi.org/10.14201/zephyrus201984115137

\title{
EL CAMPO DE TÚMULOS DE PEÑAS PASERA DE LA CIUDAD CELTIBÉRICA DE ARATIS (ARANDA DEL MONCAYO, ZARAGOZA) Y EL CALENDARIO CELTA
}

\section{The Peñas Pasera tumulus field of the Celtiberian city of Aratis (Aranda del Moncayo, Zaragoza, Spain) and the Celtic calendar}

\author{
César Esteban López*, Francisco Romeo Marugán** y Luis Fatás Fernández** \\ * Instituto de Astrofísica de Canarias. C/ Vía Láctea, s/n. 38200 La Laguna (Santa Cruz de Tenerife). Correo-e: \\ cel@iac.es. ID ORCID: https://orcid.org/0000-0002-5247-5943 \\ ** Dirección General de Cultura y Patrimonio. Gobierno de Aragón. Avda. Ranillas, 5D. 50008 Zaragoza. \\ Correo-e:fromeo@aragon.es; Ifatas@aragon.es.ID ORCID: https://orcid.org/0000-0003-2391-9418
}

Recepción: 1/06/2019; Revisión: 11/07/2019; Aceptación: 20/10/2019

\begin{abstract}
Resumen: Dentro de las actuaciones llevadas a cabo por la Dirección General de Patrimonio Cultural del Gobierno de Aragón en relación con el procedimiento judicial sobre el expolio de la ciudad celtibérica de Aratis (Aranda de Moncayo, Zaragoza), se localizó un área amplia con varias concentraciones de estructuras tumulares en la zona de Peñas Pasera, inédita hasta el momento. Se trata de una zona llana y elevada, a una cota similar a la parte alta de la ciudad y a unos $1300 \mathrm{~m}$ de distancia. La peculiar morfología de una estructura tumular de grandes dimensiones ubicada en la cota más alta de esta zona, y su presumible relación con la ciudad celtibérica, motivó su estudio arqueoastronómico. Un análisis detallado ha permitido identificar una importante cantidad de marcadores e hitos visuales que pudieron utilizarse para señalar e identificar las fechas más importantes del calendario celta. Esto abre la puerta a varias interpretaciones de la estructura y del amplio conjunto tumular localizado.

Palabras clave: Edad del Hierro; celtíberos; necrópolis; Arqueoastronomía; hitos visuales.
\end{abstract}

Авsтract: Within the actions carried out by the Directorate General of Cultural Heritage of the Government of Aragon in relation to the judicial procedure on the pillage of the Celtiberian city of Aratis (Aranda de Moncayo, Zaragoza), a large area was located with several concentrations of tumular structures in the area of Peñas Pasera, previously unpublished. It is a flat and elevated area, at a level similar to the upper part of the city and about $1300 \mathrm{~m}$ away. The peculiar morphology of a large tumular structure located at the highest level of this area, and its presumable relationship with the Celtiberian city, motivated its archaeoastronomical study. A detailed analysis has allowed to identify an important quantity of markers and visual landmarks that could be used to indicate and identify the most important dates of the Celtic calendar. This opens the door to various interpretations of the structure and of the large tumular group.

Key words: Iron Age; Celtiberian; necropolis; Archaeoastronomy; visual markers. 


\section{La ciudad celtibérica de Aratis}

\subsection{Antecedentes y situación}

El yacimiento arqueológico denominado "Castejón I-El Romeral” en la Carta Arqueológica de Aragón es un oppidum celtibérico con una superficie cercana a las 9 ha, localizado a un $1 \mathrm{~km}$ al $\mathrm{NE}$ de la localidad aragonesa de Aranda de Moncayo, en

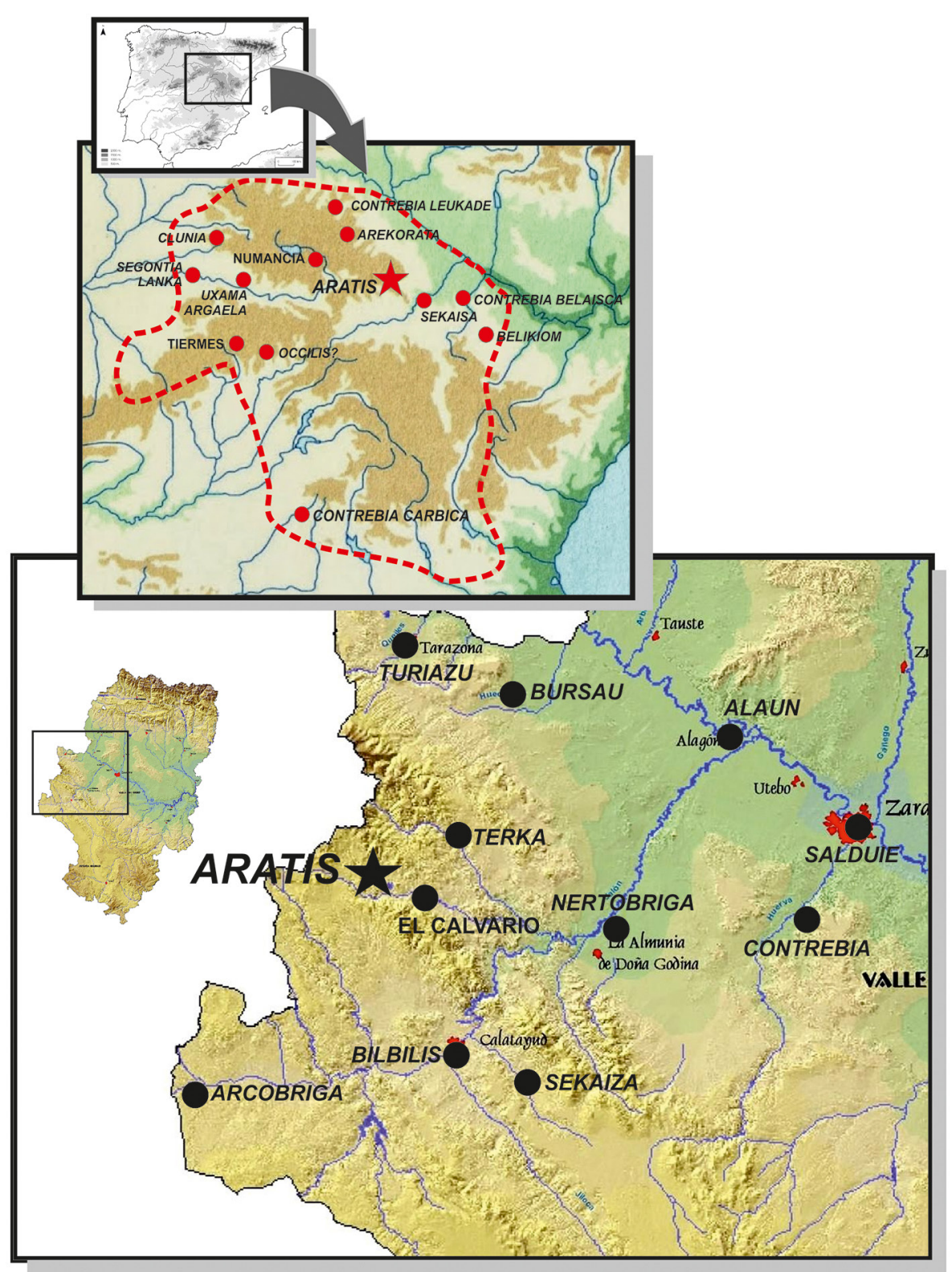

FIg. 1. Situación de la ciudad celtibérica de Aratis. la provincia de Zaragoza (Fig. 1). Se encuentra en la margen derecha del Aranda, un río que conserva el topónimo celtibérico y que da nombre a todo el valle y a esta comarca zaragozana. Los restos de la ciudad se extienden por la ladera oriental, a resguardo del cierzo dominante, en un cerro de pronunciada pendiente, denominado "Castejón" o "Peñas de Castejón”. Este yacimiento ha sido identificado, ya sin ninguna duda, como la ciudad celtibérica

que acuñó moneda con la leyenda a.r.a.ti.ko.s, término que corresponde al gentilicio de Aratis (Fatás et al., 2014: 20).

De esta ciudad procede un notable conjunto de cascos hispanocalcídicos (Graells et al., 2014), desgraciadamente conocidos por haber sido objeto de expolio y contrabando (Egg, 2002), lo que ha motivado unos amplios operativos policiales (las Operaciones Helmet I y II, coordinadas por el Grupo de Patrimonio Histórico de la Unidad Central Operativa de la Guardia Civil) y un prolijo procedimiento penal. Como consecuencia del mismo, y cumpliendo un mandato judicial, los servicios técnicos de la Dirección General de Cultura y $\mathrm{Pa}$ trimonio realizaron entre 2013 y 2016 una exhaustiva inspección del yacimiento y de su entorno, así como la práctica de varias actuaciones periciales. Esos trabajos permitieron la localización 
de varias necrópolis asociadas a la ciudad y el túmulo que aquí nos ocupa, elementos desconocidos hasta el momento. Asimismo, al conjunto de cascos expoliado, que podrían superar la veintena y que, según distintas informaciones, se habrían recuperado junto a pectorales y trípodes (Graells et al., 2014: 227-236), hay que sumar un fragmento de otro, localizado en unas prospecciones realizadas en 1993 dentro del perímetro urbano e interpretado recientemente como tal en relación a este procedimiento judicial (Fatás et al., 2014: 24).

Los trabajos que han permitido el estudio que aquí se presenta han sido promovidos por la $\mathrm{Di}$ rección General de Patrimonio Cultural del Gobierno de Aragón en ejercicio de las funciones que tiene encomendadas de prevención, protección, difusión, fomento y acrecentamiento del patrimonio cultural.

La sentencia judicial 199/2018 de la Audiencia Provincial de Zaragoza, sección sexta, de 16 de julio de 2018, recurrida ante el Tribunal Supremo en el momento de redacción de estas líneas, afirmó de forma contundente en el Punto Primero de los Hechos Probados, refiriéndose a los cascos, que estos están "datados entre los siglos v a II a. C., tratándose en todo caso de piezas de excepcional valor científico, histórico y cultural, de producción celtíbera con características morfológicas técnicas y decorativas propias, original variante hispánica de los cascos grecocalcídicos y con un origen y distribución exclusivo en la Península Ibérica y en concreto procedentes del yacimiento de la ciudad celtíbera de Aratikos sita hoy en día en el término municipal de Aranda del Moncayo (Zaragoza)".

La ciudad se sitúa en una zona geológica que pertenece a la Cordillera Ibérica, al s del Moncayo (Fig. 1). En esta área afloran en superficie depósitos de todas las Eras, aflorando los niveles de las facies Bustsandstein. Estas facies están formadas por sedimentos de conglomerados y microconglomerados con intercalaciones de areniscas a los que les siguen sedimentos de areniscas rojas de grano fino con matriz arcillosa y la serie con limolitas y arcillas con finas intercalaciones de areniscas. Esto resulta de trascendental importancia dada su relación con la

(C) Universidad de Salamanca presencia de mineralizaciones de plomo, plata, cobre y, sobre todo, hierro (Romeo, 2016: 65).

Pese a la gran relevancia y los imponentes restos que conserva este yacimiento, su aparición en la bibliografía ha sido realmente anecdótica hasta fechas recientes (Fatás et al., 2014: 19-21), ampliándose, como hemos comentado, su conocimiento y difusión a consecuencia de su ya comentado expolio y sus consecuencias. No obstante, fue la numismática la que permitió una primera aproximación al conocimiento de la existencia de esta ciudad, cuando a mediados del s. xx Beltrán (1950: 325) propuso Aranda de Moncayo o Aranda de Duero como origen de las monedas con la leyenda a.r.a.ti. ko.s. Propuestas posteriores la situaron siempre en el ámbito celtibérico (Gil Farrés, 1966: 160-162; Untermann, 1975: 275-276; Guadán, 1980: 194195), teniendo que esperar a finales del s. Xx para que tomase cuerpo la identificación del yacimiento de Aranda de Moncayo como la ceca emisora de estas monedas (Fatás et al., 2014: 20).

Los datos extraídos de las diferentes intervenciones arqueológicas realizadas sobre esta ciudad, pendientes de publicación, así como los materiales cerámicos recogidos en las diferentes campañas de prospecciones, especialmente las cerámicas de barniz negro, permiten postular un origen para la misma hacia finales del s. viI a. C. o comienzos del vi a. C. y su desaparición a finales del s. II o comienzos del i a. C. (Fatás et al., 2014: 30-31), casi con toda seguridad a finales del primer cuarto del s. I a. C. en el contexto de la guerra de Roma contra Sertorio, al igual que en el próximo yacimiento celtibérico de "El Calvario", un asentamiento a $10 \mathrm{~km}$ de Aratis, tal vez dependiente de esta ciudad (Romeo, 2016: 85).

\subsection{El sistema defensivo y otras estructuras monumentales}

El elemento más relevante de la ciudad de Aratis es sin duda su sistema defensivo, perceptible en la fotografía aérea a simple vista, un sistema complejo, organizado y presidido por una gran estructura de planta cuadrada, de $21 \mathrm{~m}$ de lado aproximadamente,

Zephyrus, LXXXIV, julio-diciembre 2019, 115-137 


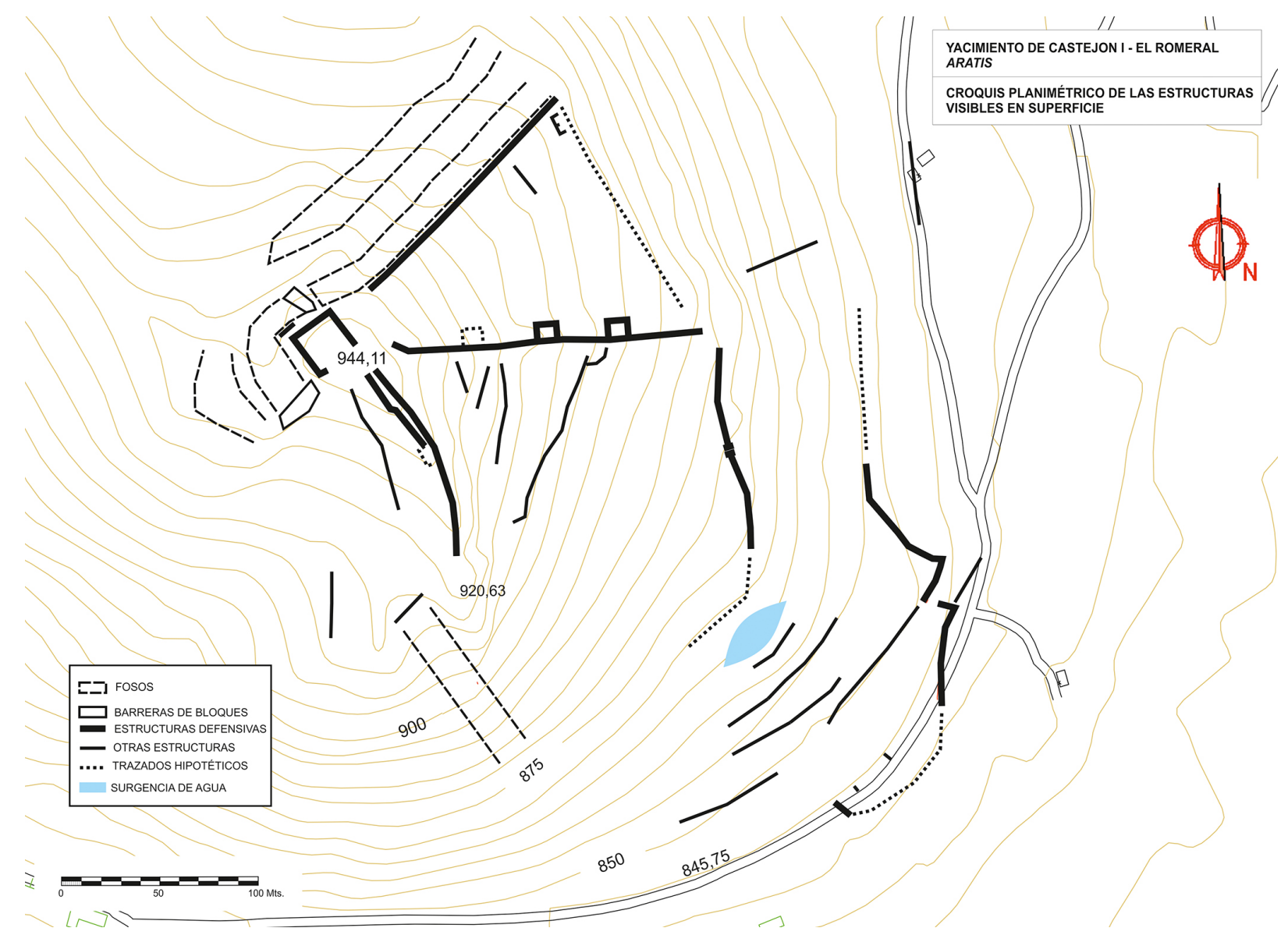

Fig. 2. Croquis planimétrico de la ciudad de Aratis.

situada en la cota más alta (Fig. 2). Este gran edificio muestra en superficie muros de hasta $2 \mathrm{~m}$ de altura, construidos con un aparejo de grandes dimensiones, un opus quadratum seudoisódomo de posible filiación itálica, completamente distinto del usado en el resto de murallas y que se aparta de la tradición constructiva celtibérica (Romeo, 2002: 169). Su morfología y notables paralelos nos han llevado a identificarla como una turris de cronología y factura romana republicana (Fatás et al., 2014: 27-30) que se superpone y preside la ciudad celtibérica, un apasionante asunto en el que no vamos a entrar en este estudio.

El desarrollo cronológico de la ciudad se plasma en su sistema defensivo, ya que se pueden identificar elementos correspondientes al menos a dos momentos distintos. Los lienzos de muralla que conservan torres a intervalos casi regulares son los más antiguos de este sistema defensivo, y defenderían un primer núcleo urbano de la ciudad situado en la zona más elevada de la ladera, con una superficie de 2,3 ha (Fig. 2). El lienzo que parte de la cota más alta de este primer núcleo urbano hacia el sureste se prolonga $135 \mathrm{~m}$; con $2 \mathrm{~m}$ de grosor, está realizado con sillares de caliza, en ocasiones de más de 1,50 m de longitud. Esta muralla posee torres de planta rectangular de $6 \mathrm{~m}$ de lado dispuestas cada $30 \mathrm{~m}$ aproximadamente. El lienzo de muralla que protege el yacimiento al norte recorre $125 \mathrm{~m}$ hasta perderse. Idéntico en su morfología a la muralla anterior, posee al menos dos torres. El lienzo de muralla que cerraría la ciudad por el este y el sur discurriría próximo a un marcado cantil de la roca, que aparece retallado a tal fin intencionadamente 
en ciertas zonas, aunque se encuentra prácticamente desaparecido.

La ampliación de la ciudad hacia el $\mathrm{N}$ y el E supuso la construcción de un nuevo recinto defensivo, manteniendo el primer lienzo descrito, construyendo nuevas líneas de muralla y amortizando los lienzos norte, este y sur, anteriormente descritos, que quedaron intramuros. Este segundo recinto amplió la ciudad a una superficie mínima de 7,5 ha, en un momento que podemos situar a grandes rasgos en la segunda mitad del siglo III a. C. Un nuevo lienzo de muralla cerró por el norte la ciudad, bajando desde la turris por la ladera $128 \mathrm{~m}$ hacia el NE. Se trata de una muralla sin torres, fabricada con sillares de caliza y una anchura de un mínimo de $1 \mathrm{~m}$. Se encuentra defendida por dos fosos paralelos de entre 15 y $20 \mathrm{~m}$ de anchura cada uno (Fig. 2). Al e y al s la muralla se pierde, muy posiblemente desmontada para reutilizar sus piezas en la construcción de un convento próximo, conservándose sobre todo en las cercanías de lo que se ha identificado con pocas dudas como una puerta monumental de 3,60 m de anchura (Graells et al., 2014: 220-221). En esta zona el aparejo aparece formado por grandes ortostatos, una morfología coherente con la baja cronología propuesta, tal y como se está poniendo de

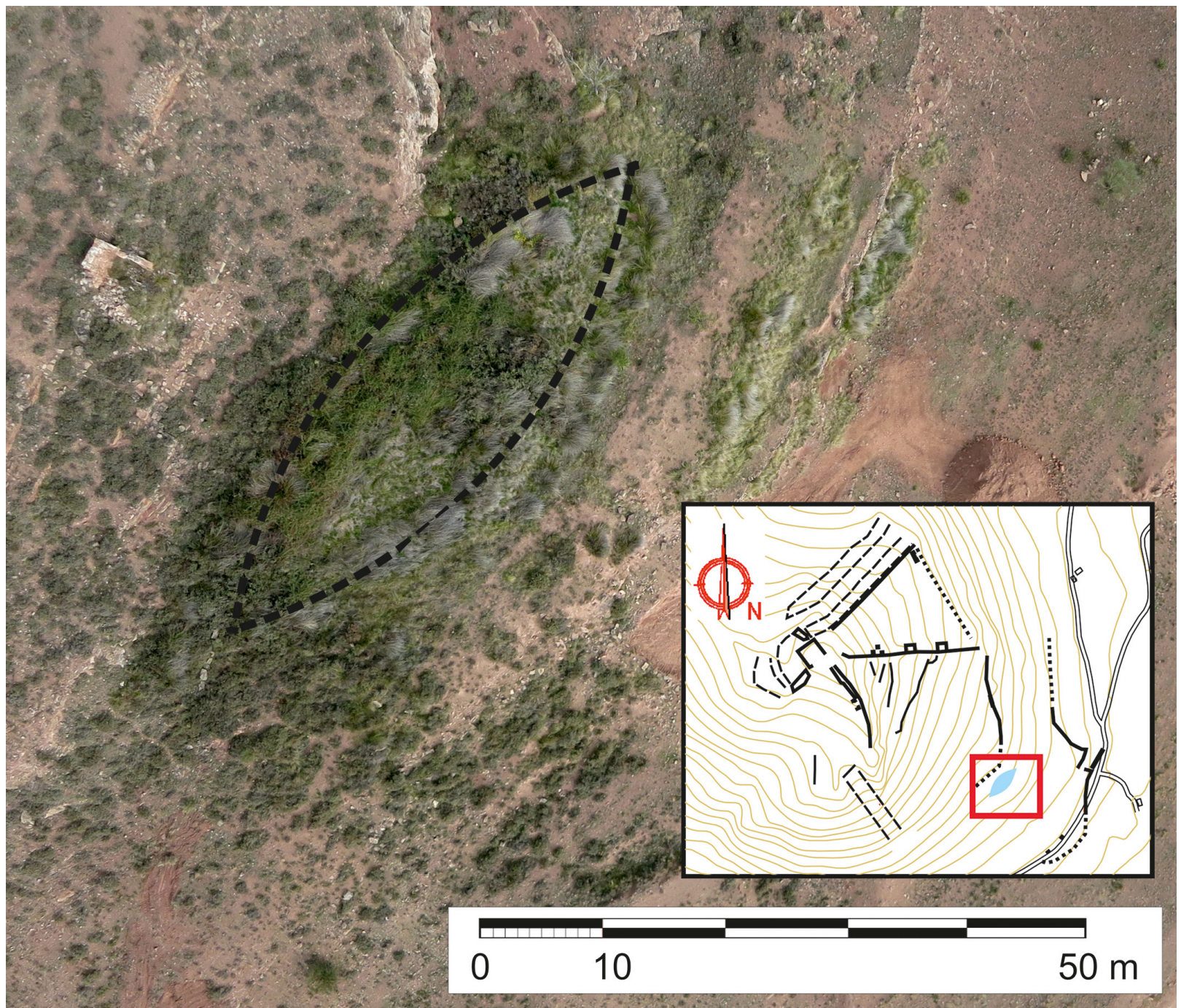

FIG. 3. Posible estructura monumental de depósito de agua. 
manifiesto en numerosos yacimientos del s. II a. C. (Romeo, 2015: 352). La presencia de la estructura que preside todo el sistema defensivo en la cota más alta del yacimiento hay que ponerla necesariamente en relación con la presencia de Roma y su control de esta zona peninsular (Romeo, 2018: 186-187), un tema interesante, pero que se aparta del objeto del presente trabajo.

$\mathrm{La}$ estructura que aparece en relación con una surgencia de agua permanente en el interior de la ciudad evidencia y pone de manifiesto la relevancia de Aratis. La fotografía aérea (Fig. 3) permite reconocer una planta de tendencia fusiforme dibujada por una marcada línea de densa vegetación, sin duda de factura antrópica y que puede identificarse sin dudas como un aljibe, estanque o depósito de agua (Graells et al., 2014: 255). La surgencia continua de agua ha sido utilizada como abrevadero para el ganado hasta fechas recientes, según la información oral recabada, que afirma que el agua fluía todo el año. La presencia de sillares de grandes dimensiones en el entorno inmediato de este elemento parece estar indicando la relevancia de esta zona y el probable carácter monumental de unas estructuras pendientes de identificar, lo cual resulta tremendamente sugerente, sobre todo en relación al hallazgo de los cascos hispanocalcídicos (Graells y Lorrio, 2013). No obstante, y pese a no haberse realizado ninguna intervención arqueológica sobre el terreno, la planta dibujada por la vegetación permite reconocer unas dimensiones aproximadas de $44 \mathrm{~m}$ de longitud y 14,5 m de anchura máxima y su forma parece responder a la intersección de dos círculos cuyo radio correspondería al eje máximo de la citada planta.

\subsection{La ciudad de Aratis y la metalurgia}

Resulta muy significativa la presencia de bloques de escoria dispersos por toda la superficie de la ciu$\mathrm{dad}$, incluso en cotas altas de la ladera, procedentes de procesos de trasformación y forjado de hierro y bronce. Su presencia en el yacimiento es constante, lo que nos lleva a concluir que la ciudad de Aratis estuvo estrechamente vinculada con la metalurgia,

(C) Universidad de Salamanca siguiendo patrones de otros yacimientos celtibéricos (Lorrio, 1997: 304; Martínez Naranjo y Arenas, 1999: 203).

Las numerosas de minas hierro y cobre en el valle del río Aranda, junto a la existencia de próximos yacimientos de la misma cronología que conservan restos de hornos de fundición, como en El Calvario de Gotor (Romeo, 2016: 66), indican que la actividad metalúrgica era muy intensa en el valle del río Aranda. Esta especialización metalúrgica da sentido a las abundantes citas clásicas que hablan de los celtíberos como excelentes fabricantes de armas ${ }^{1}$; un dato de gran interés, dado el hallazgo del destacado conjunto de cascos hispanocalcídicos en el yacimiento.

Las mineralizaciones de hierro y cobre en el valle del río Aranda son numerosas (Montero et al., 1999: 164; Polo, 1999: 198). De tipo estratiforme, aparecen sobre afloramientos paleozoicos pertenecientes al Cámbrico superior, bajo la forma de oligisto y goethita (Mata, 1989: 167). En el mismo término municipal de Aranda de Moncayo, en las inmediaciones de la ciudad de Aratis, se localizan varias minas de hierro que han sido explotadas hasta fechas recientes (Romeo, 2016: 85-86).

El patrón de ocupación en época celtibérica plena y tardía de este valle del río Aranda está definido y dibujado así por la obtención y el trabajo de los metales, estando en condiciones de afirmar que Aratis ejercería la capitalidad de esta área, con una dedicación prioritaria a la producción y elaboración de objetos metálicos. Las prospecciones y las intervenciones arqueológicas realizadas en El Calvario de Gotor, y en la misma ciudad que nos ocupa, indican que en esta se concentraría, manufacturaría y distribuiría la producción metálica en hierro y bronce de esta comarca, sobrepasando con creces las necesidades locales (Romeo, 2016: 87). Se trata de productos de alto valor económico, que sin duda proporcionaron a esta comarca, y a la ciudad de Aratis en particular, un gran potencial y relevancia en la Celtiberia, que no pudo pasar inadvertido a los intereses de Roma en el s. II a. C.

1 Diod. Sic., 5, 33, 3-4. 


\subsection{Las necrópolis de Aratis}

El estudio llevado a cabo para contextualizar la ciudad en su territorio permitió determinar la existencia de varias necrópolis en su entorno (Fig. 4). Antes de nada, hay que señalar que el severo expolio sufrido y la ausencia de trabajos sistemáticos no permiten determinar su interrelación, por lo que no podemos aventurar si las diferentes zonas responden a criterios temporales, simbólicos, sociales, de género o familiares.

La necrópolis localizada en la zona conocida como Collado de las Viñas está conformada por una serie de túmulos entre los que destacan varios de grandes dimensiones que aparecen alineados sobre la cresta del espolón donde se ubican, que se sitúa a $950 \mathrm{~m}$ al norte de la ciudad y se eleva 45 $\mathrm{m}$ sobre su entorno. Los túmulos están realizados a partir de lajas de piedra dispuestas de modo radial, pudiendo reconocerse en su interior una cámara o cista, que permite su identificación como estructuras funerarias. Todas ellas aparecen expoliadas en fechas relativamente recientes como ponen de manifiesto grandes ortostatos desplazados sobre tierra vegetal, lo que contrasta con la práctica ausencia de material cerámico o metálico, una situación que se explica por los patrones del intenso y sistemático expolio sufrido por esta zona durante más de tres décadas, un expolio que conllevó la recogida exhaustiva de todo tipo de fragmento metálico de cronología antigua, independientemente de su tamaño o morfología.

La necrópolis del Collado de las Viñas conserva un elemento de notable interés, la plataforma sobre la que se asienta aparece delimitada en su flanco norte por los restos de un muro formado por una doble hilada de ortostatos de grandes dimensiones hincados verticalmente que delimitan un relleno interior. La estructura y morfología de este muro se aparta radicalmente de las tipologías de todos los muros de cualquier cronología realizados para construir estructuras, delimitar, compartimentar o abancalar el territorio en esta zona de la serranía ibérica (Marco y Rivas, 2003: 22-37), con una excepción; en la zona superior de la ciudad de Aratis, se han localizado muros conformados por ortostatos con el mismo sistema constructivo. Esta similitud con estructuras pertenecientes a la ciudad hace posible asociar esta estructura a la necrópolis,

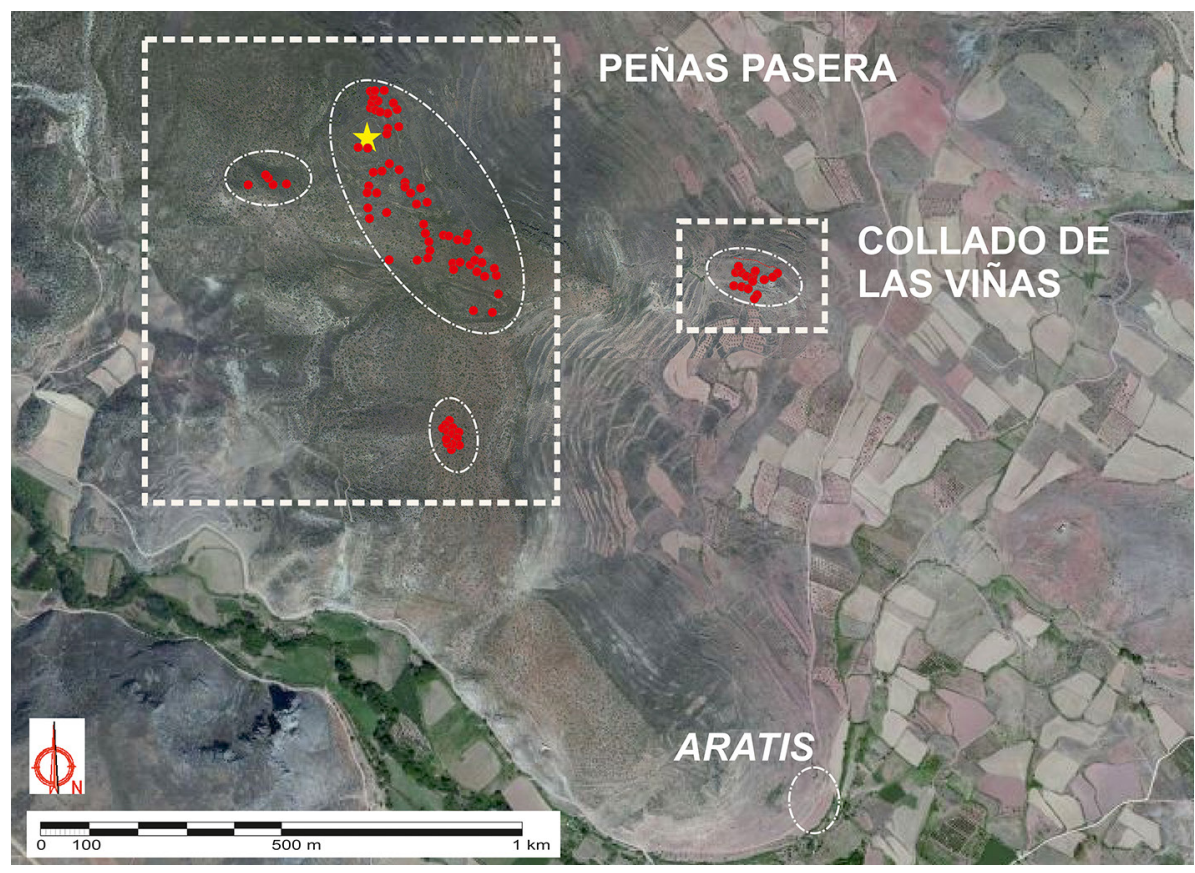

Fig. 4. Zonas de necrópolis. pudiendo constituir una delimitación, a modo de temenos, del área funeraria, un tema sobre el que no vamos a entrar en este trabajo.

La excavación arqueológica realizada en una zona del interior de la ciudad que presentaba un desmonte de tierras realizado con medios mecánicos, dentro de los trabajos periciales asociados al procedimiento judicial, permitió identificar otra necrópolis perteneciente a una primera fase de la ciudad de Aratis, que fue absorbida y amortizada 
parcialmente por el crecimiento y desarrollo urbanístico de la ciudad en un momento del III a. C. Esta necrópolis se extiende hasta el exterior de la última línea de muralla. Se trata de un área que se ha detectado puntualmente y sobre cuya descripción no podemos extendernos ante las circunstancias procesuales de su hallazgo.

\section{Los campos tumulares de Peñas Pasera}

Como hemos señalado, la zona de Peñas Pasera se localiza al noroeste de la ciudad celtibérica de Aratis -al n de la actual Aranda de Moncayo-, a una distancia de entre 1 y $1,5 \mathrm{~km}$. Su identificación se produjo a consecuencia de las actuaciones periciales ya comentadas, debido a noticias orales recabadas que comentaban la presencia de estructuras en esa zona.

A lo largo de la superficie elevada de Peñas Pasera se localizan hasta tres grupos de estructuras tumulares distribuidas en este paraje (Fig. 4), unas zonas con diferentes densidades y sin aparente organización interna, al menos en estos momentos del estudio, salvo la existente al norte de la plataforma, donde hasta nueve túmulos parecen presentar cierta disposición ortogonal. En ninguna de estas zonas se ha observado la presencia de elementos complejos de organización interior, calles o estelas como las documentadas en Inchidero (Arlegui, 2012) o Herrería (Cerdeño et al., 2001-2002: 257) entre otros ejemplos.

Tipológicamente, la mayor parte de estas estructuras están conformadas por túmulos de piedra con un diámetro variable entre uno y dos metros, realizados en una mampostería homogénea, que evidencia una selección de las piezas utilizadas, reconociéndose en ocasiones un anillo exterior conformado por sillarejos someramente careados de mayor tamaño (Fig. 5). Se reconoce de este modo una estructura intencionada, una construcción y no

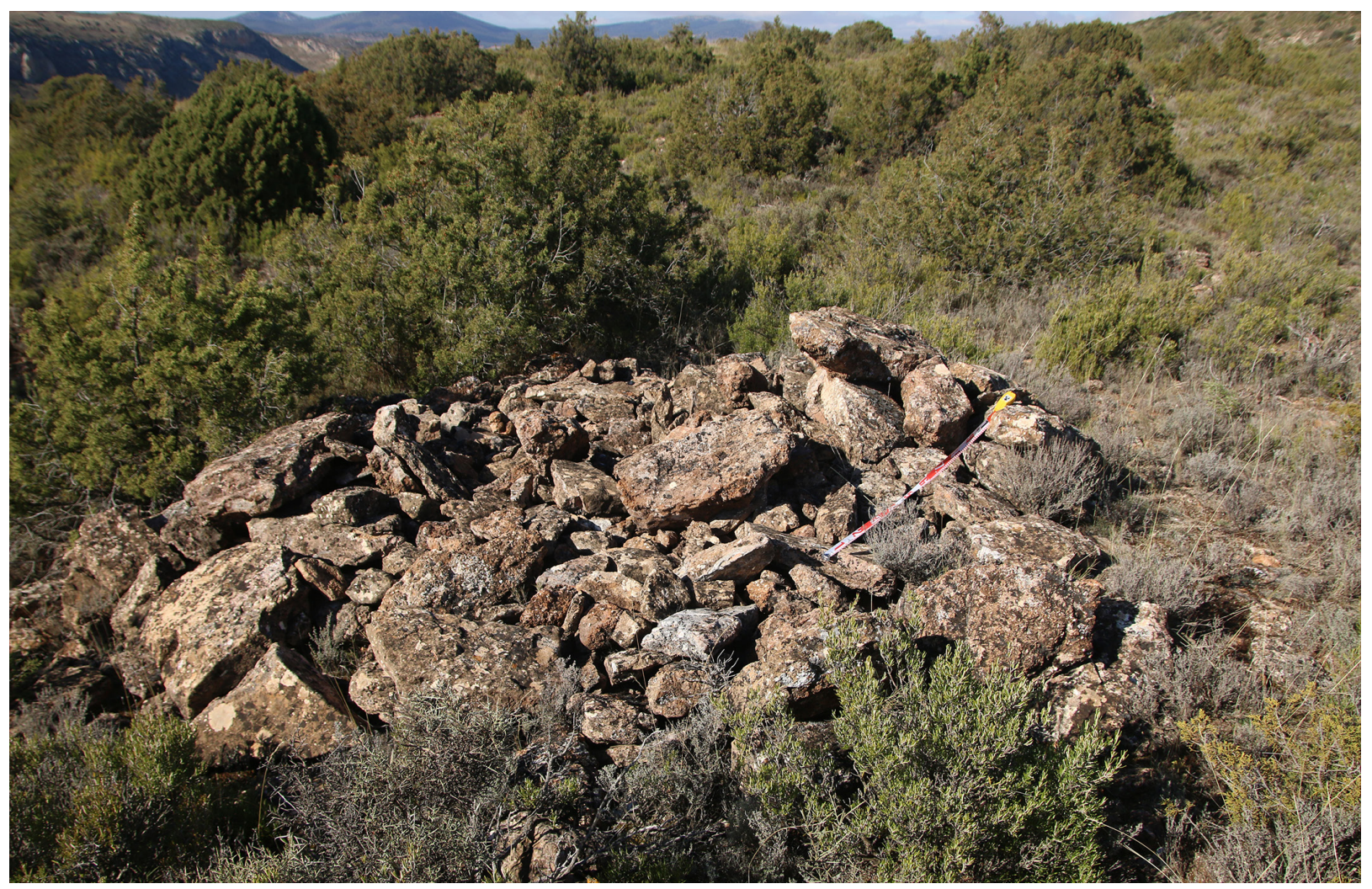

Fig. 5. Ejemplo de túmulo conservado en Peñas Pasera. 
el fruto de un simple amontonamiento de piedras. Otra tipología reconocible es similar a la descrita en la necrópolis del Collado de las Viñas; lajas dispuestas radialmente. El estado de conservación de estas estructuras es variable, con ejemplos bien conservados, aunque en cualquier caso no se han podido reconocer directamente cistas, aunque no deja de ser revelador el crecimiento diferencial de la vegetación, con ejemplares de mayor porte, habitualmente enebros o retamas, en el centro de buena parte de estas estructuras. El reconocimiento superficial del terreno no ha permitido tampoco identificar materiales en superficie que nos permitan identificar la cronología de estas estructuras, debido a las condiciones del terreno; la altitud de esta zona, a 1033 m s.n.m.; su total exposición a los agentes atmosféricos, y el duro régimen climático y pluviométrico de esta zona, junto con la ausencia total de pastoreo en la misma, explican esta proliferación de vegetación de distinto porte que tapiza el suelo y la roca y dificulta enormemente la prospección visual con la metodología habitual.

A falta de una intervención arqueológica detallada sobre el conjunto de Peńas Pasera, los únicos indicios de organización que se aprecian son

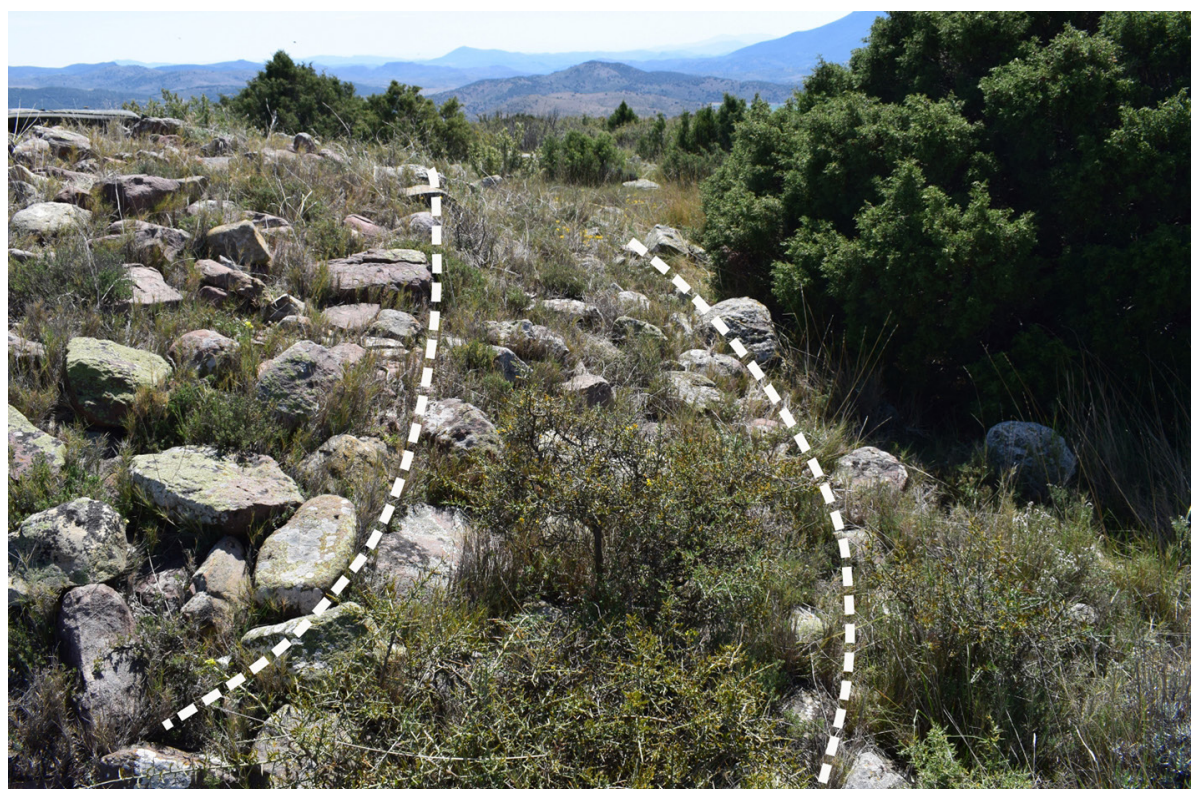

Fig. 6. Detalle del túmulo principal; los dos anillos concéntricos marcados con líneas discontinuas. la presumible jerarquización que marca el túmulo principal y de mayores dimensiones, identificado con una estrella en la Fig. 4, y la ya comentada disposición ortogonal de una serie de túmulos en su entorno inmediato, al norte. Dicho túmulo se sitúa en la cota más alta de esta área, a 1033 m s.n.m., lo que permite un control visual muy significativo. Su situación, plenamente determinada por el relieve circundante, evidencia un estudio previo del terreno, un trabajo dirigido a subrayar la importancia de esta estructura y, como veremos inmediatamente, un conocimiento astronómico.

El análisis superficial permite reconocer un túmulo circular, de entre 10 y $11 \mathrm{~m}$ de diámetro, formado por un doble anillo concéntrico en su base (Fig. 6) destinado a sostener y estabilizar la mampostería del túmulo. Estos anillos están formados por sillarejos careados de dimensiones variadas, en ocasiones de tamaño considerable. Por último, hay que destacar la presencia en el interior de esta estructura de un muro de unos $60 \mathrm{~cm}$ de grosor, formado por dos lienzos con relleno interior, que cruza el túmulo diametralmente en dirección NE-SO (Fig. 7) y que ha sido el elemento detonante para la identificación de las características peculiares de esta estructura y la publicación del presente trabajo.

En el entorno del túmulo se conservan los restos de una estructura cuadrangular cuyos muros llegan a alzarse más de un metro en algún punto, realizados con mampostería. Se trata de una estructura de cronología reciente que fue abandonada, según la información recabada, tras la Guerra Civil española y que puede estar en relación con la explotación agrícola de una reducida zona en la ladera norte de Peñas Pasera, reconocible en las fotografías aéreas 
de 1945. En ningún punto pudimos localizar elementos cerámicos o de otro tipo que nos permitiesen mayor precisión cronológica, dada la abundante vegetación que tapiza todo el suelo, como ocurrió con las estructuras tumulares.

La interpretación de la función y cronología de estas estructuras tumulares dista mucho de ser sencilla, y no ha podido solventarse con una intervención arqueológica ni con la utilización de medios de detección no invasivos dada la situación administrativa y procesual de este yacimiento, incurso en un procedimiento judicial todavía sin concluir, como ya hemos comentado. El no haber podido localizar ningún fragmento cerámico o pieza arqueológica que permita identificar estas zonas con absoluta seguridad como necrópolis de Aratis constituye sin duda un grave problema, al que nos hemos tenido que enfrentar valorando y analizando todo tipo de variables y posibilidades en relación con la cronología e interpretación de estas estructuras tumulares.

Si bien la situación en una zona llana pero elevada supone un patrón de ubicación poco habitual en las necrópolis celtibéricas del área meseteña (Lorrio, 1997: 111-112), no lo es tanto en zonas relativamente próximas pertenecientes al ámbito ibérico, como en $\mathrm{El}$ Cascarujo de Alcañiz (Benavente et al., 2012: 41-43) o incluso en cronologías de la Edad del Bronce, con necrópolis como El Monsacro, en Asturias (Suárez, 2019: 276). Resulta sumamente interesante la aportación de Liceras (2017: 101-102), quien, atendiendo a las distribuciones de las necrópolis de la primera Edad del Hierro, subraya la "ocultación de los espacios funerarios en las zonas de montaña", como elemento diferenciador de la ubicación de las necrópolis entre los grupos de las zonas de montaña del Sistema Ibérico, como el que nos ocupa, y los de los valles. La ausencia del conocimiento de la situación exacta de la mayor parte las necrópolis de los hábitats de esta abrupta zona de la sierra del Moncayo, con una orografía tortuosa, junto con la similitud de la altitud de esta área con la de la zona superior de la ciudad de Aratis, con la que se conecta y pone en relación directa gracias a un acceso sencillo relativamente llano, hacen posible la interpretación de estas estructuras como funerarias; de hecho, desde la zona alta de la ciudad hasta Peñas Pasera únicamente se ascienden $50 \mathrm{~m}$ para $1150 \mathrm{~m}$ de

(C) Universidad de Salamanca longitud. En este mismo sentido no hay que olvidar que la próxima necrópolis del Collado de las Viñas se ubica, como hemos visto, en una elevación destacada sobre su entorno y que los túmulos dispuestos en su zona superior bien pudieron cumplir algún tipo de función de marcador visual como se ha observado en otros ámbitos próximos (Graells, 2008: 40; Baquedano, 2013: 754; Faro, 2015: 33) ${ }^{2}$.

Morfológicamente, los túmulos no se aproximan a ninguna estructura tradicional $\mathrm{u}$ otro elemento etnográfico de la zona del Moncayo o de la Sierra Ibérica. Se ha valorado su interpretación como restos de estructuras asociadas al pastoreo pertenecientes a una tipología específica y típica del Moncayo de planta circular: las casillas de pico (Marco y Rivas, 2003); pero tanto las dimensiones de estas casetas, de entre cuatro y seis metros de diámetro, como su patrón y densidad de aparición en un área, o su misma morfología, sin la presencia de anillos estructurales en su base, indican que se trata de elementos totalmente diferentes. Por otra parte, tampoco se pueden identificar como amontonamientos de piedras producidos a consecuencia de la preparación de una zona para su explotación agrícola, tanto por su morfología constructiva intencionada (vid. supra) como por el hecho de que buena parte de estos elementos aparecen en zonas donde aflora la roca y no ha existido suelo vegetal que permitiera el cultivo. Además, en las reducidas zonas de Peñas Pasera donde sí se produjo una explotación agrícola aparecen, en cambio, potentes muros o cordones de piedras que delimitan y rodean los campos que se construyeron como resultado de 'despedregar' el terreno, en lugar de estructuras tumulares. No se ha identificado de este modo con ningún tipo de estructura tradicional, etnográfica ni como resultado de una transformación del terreno o paisaje que explique ni se aproxime siquiera a estas estructuras tumulares.

Tampoco parecen ponerse en relación con la trashumancia o pastoreo como se ha sugerido en otros casos, como los amontonamientos de piedras de Villanueva de Cameros; la situación en altura de esta zona hace que nunca haya sido transitada por los pastores

2 También Baquedano, I.: La necrópolis vetona de La Osera (Ávila, España): sistematización del conjunto. Tesis doctoral presentada en 2013 en la Univ. Complutense de Madrid. 
de la zona, hecho que pudimos contrastar en varias entrevistas orales; de hecho, los pastores la han evitado tradicionalmente por lo expuesto de la misma a vientos y tormentas, y porque allí "no crece nada bueno, no es buena tierra". Del mismo modo su interpretación como apostaderos de caza recientes o cualquier otro tipo de uso funcional se ha descartado dada su morfología, su densidad de aparición y su situación en una zona elevada pero relativamente llana.

La situación de estos túmulos a cierta distancia de la ciudad y no en sus inmediaciones, como en los casos de los túmulos no funerarios de El Alto del Arenal de San Leonardo o el Castro del Zarranzano, supone un elemento diferenciador con estos últimos, aunque no por ello deba descartarse taxativamente su posible relación funcional, desconocida por el momento.

En definitiva, el único elemento que arroja una potente sombra de duda sobre la cronología y función de estas estructuras tumulares es la ausencia de materiales arqueológicos en superficie, una ausencia significativa que puede explicarse por los motivos ya comentados y que esperamos que, una vez concluido el procedimiento judicial, pueda solucionarse con actuaciones arqueológicas específicas. No obstante, las características de este conjunto de estructuras tumulares y los relevantes resultados del estudio arqueoastronómico del gran túmulo de la cota nos han llevado a considerar su más que probable vinculación a cronologías protohistóricas.

\section{Estudio arqueoastronómico}

El trabajo de campo se realizó el 16 de mayo de 2017 y se centró en la medida de dos tipos de

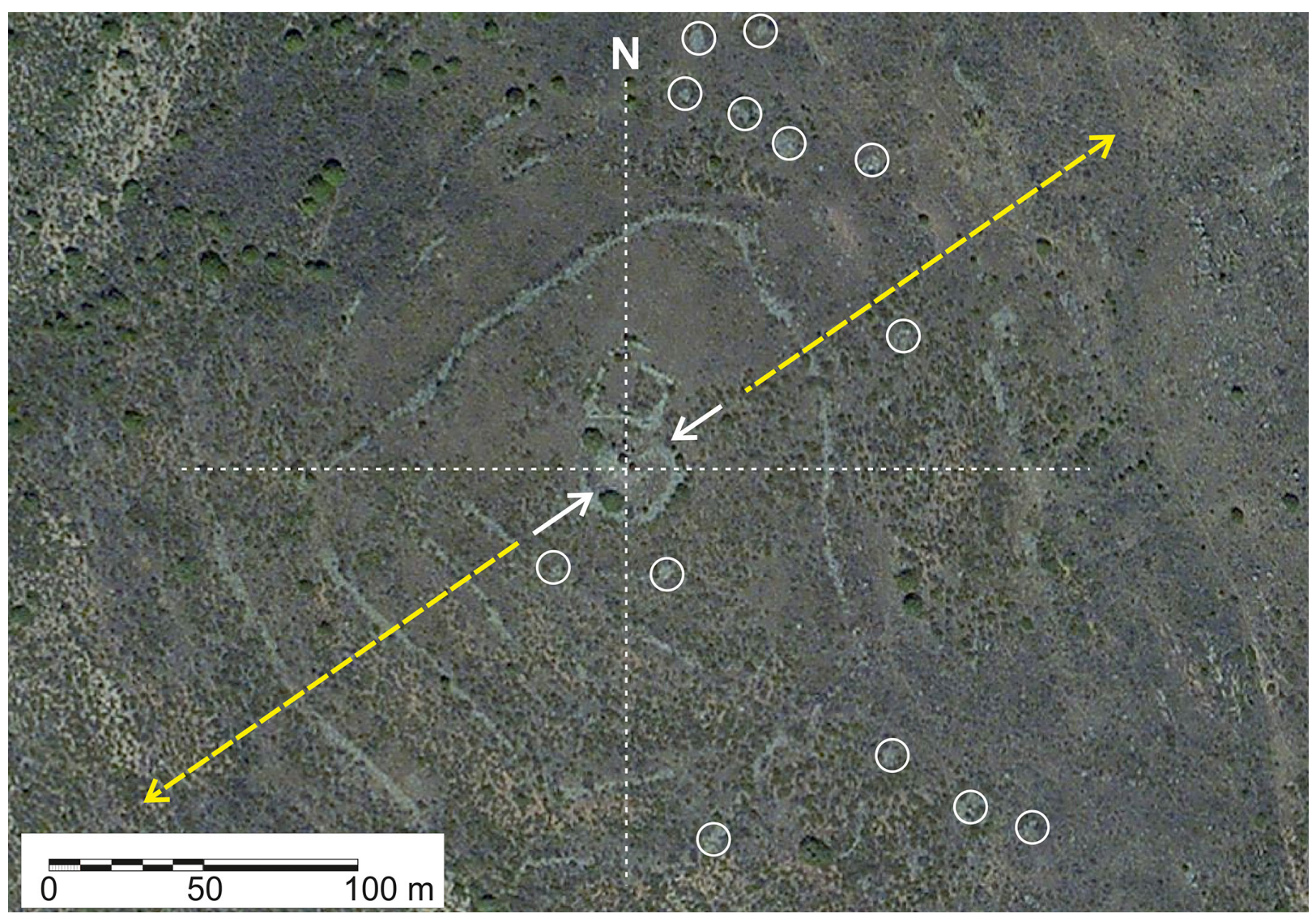

FIG. 7. Vista aérea del túmulo principal con la situación y orientación del muro diametral; señalados con círculos otros túmulos menores. 
datos: en primer lugar, la orientación de elementos arquitectónicos rectilíneos que se encontraban en superficie, sobre todo un muro que cruzaba diametralmente el túmulo, y, en segundo, de la posición de rasgos topográficos destacables del horizonte desde el mismo como picos de montaña o intersecciones entre laderas de montańas contiguas. $\mathrm{El}$ instrumental utilizado fue un teodolito, una brújula tándem de precisión -que incorpora un clinómetro-, un receptor GPS de navegación y una cámara fotográfica digital (Fig. 8).

El único elemento rectilíneo

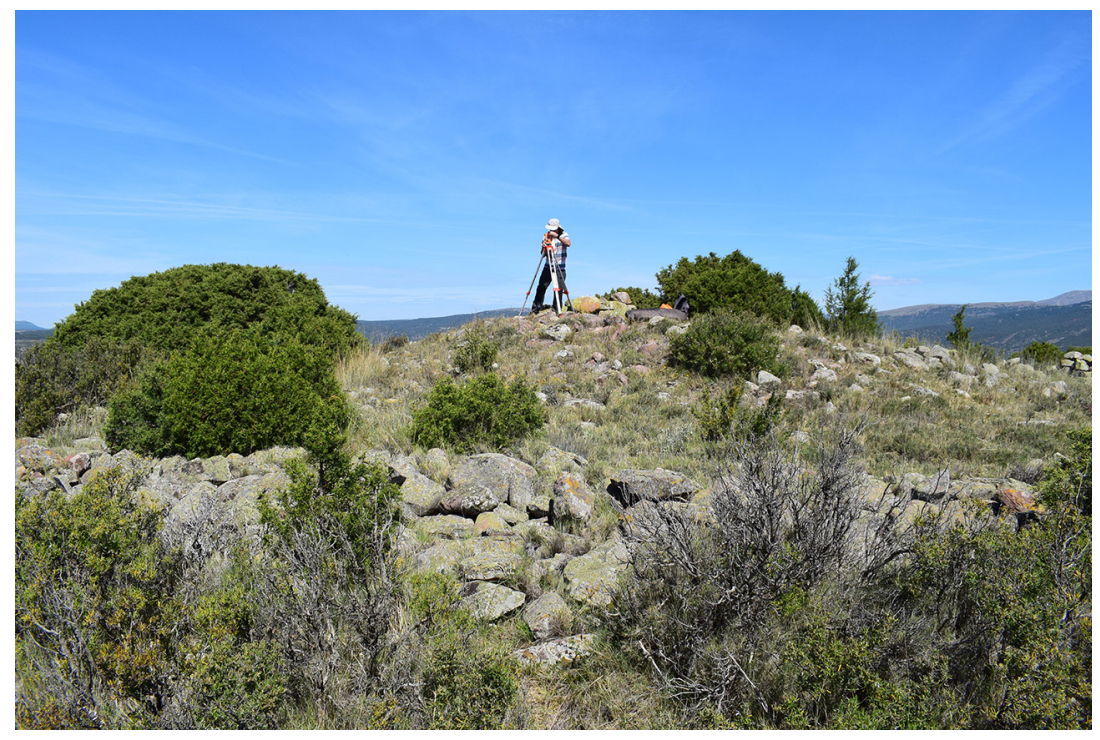

FIG. 8. Desarrollo de los trabajos sobre el túmulo principal.

en superficie del que pudimos establecer su orientación fue el citado muro que parte diametralmente el túmulo principal en dirección NE (Fig. 7). La determinación del acimut o ángulo horizontal respecto al norte geográfico de dicho muro se realizó con la brújula de precisión. El teodolito se colocó en el centro aproximado de dicho túmulo y se utilizó para medir las coordenadas horizontales: acimut $-A-\mathrm{y}$ altura sobre el horizonte $-h-$-, de un gran número de elementos topográficos relevantes. El túmulo principal se encuentra situado justo en la cumbre del cerro de Peñas Pasera, una destacada elevación llana sobre la que se extiende, como hemos visto, un amplio campo de estructuras tumulares asociadas a la ciudad celtibérica de Aratis, por lo que goza de una extraordinaria visibilidad, dominando $\operatorname{los} 360^{\circ}$ del horizonte hasta grandes distancias. Los ángulos horizontales medidos con el teodolito se transformaron a acimuts referidos al norte geográfico mediante medidas de la posición del centro del disco solar cronometradas con el GPS, que también proporciona el Tiempo Universal preciso. Se midió el ángulo horizontal de varios elementos topográficos con ambos instrumentos, brújula y teodolito. La diferencia promedio entre los acimuts medidos con el teodolito y los ángulos horizontales obtenidos con la brújula nos proporciona la declinación magnética, que resultó ser de $-0,7^{\circ} \pm 0,4^{\circ 3}$. Esta es la magnitud que hay que sumar algebraicamente para transformar los ángulos medidos con la brújula a acimuts. Con dicho valor de la declinación magnética se corrigió el ángulo horizontal medido para el muro que parte del túmulo principal obteniendo así el acimut que define su orientación.

A partir del par de coordenadas acimut y altura de los puntos del horizonte medidos con el teodolito o con la brújula y conocida la latitud, obtenida con el GPS, podemos calcular la declinación celeste ${ }^{4}$ $-\delta$ - del astro que tiene su orto u ocaso por dicho

3 La declinación magnética que suministra la página web del Centro Nacional de Información Geográfica -Instituto Geográfico Nacional- para el lugar y la fecha que nos ocupan es de $-0,3^{\circ} \pm 0,4^{\circ}-$ el signo negativo indica que el $\mathrm{N}$ magnético se encuentra desplazado hacia el o del geográfico-. Como vemos hay una pequeña diferencia entre ambas cantidades $\mathrm{de} \approx 0,4^{\circ}$, aunque son enteramente consistentes teniendo en cuenta las incertidumbres y que el valor proporcionado por la web corresponde a un cálculo basado en modelos.

4 La declinación corresponde al ángulo sexagesimal entre un astro y el ecuador celeste medido a lo largo del círculo máximo que pasa por los polos celestes y dicho astro. Es una de las coordenadas ecuatoriales -junto con la ascensión recta- que se utilizan para localizar los astros sobre la esfera celeste, el rango de valores posibles varía de $+90^{\circ}$ a $-90^{\circ}$. 
punto a través de una sencilla ecuación de transformación de coordenadas -ecuación 5 de Esteban y Moret (2006)-.

\subsection{Resultados}

En la Fig. 9 vemos que, desde el centro del túmulo principal, el muro de piedra apunta hacia la ladera norte del Alto del Marojal. El acimut medido con la brújula para dicho muro es $A=55^{\circ} \pm 2^{\circ}$ y la altura del punto del horizonte que corresponde con ese acimut es $h=0,5^{\circ} \pm 0,3^{\circ}$. La declinación resultante es $+25,4^{\circ} \pm 1,4^{\circ}$, cercana al orto solar en el solsticio de verano, correspondiente a una declinación de $+23,7^{\circ}$ a mediados del primer milenio a. C., época aproximada de la aparición de Aratis. La incertidumbre de $2^{\circ}$ que asignamos al acimut del muro proviene de la combinación del error instrumental de $1^{\circ}$ de las medidas de la brújula y la precisión que estimamos en la definición del eje de simetría del muro en su estado de conservación actual. Aparte de los criterios cuantitativos, la Fig. 9 muestra la correspondencia visual entre el muro y el orto solar del solsticio de verano a ojo desnudo, incluso tampoco podríamos descartar una orientación hacia el lunasticio mayor sur, la posición más septentrional que puede alcanzar la Luna $-\delta=+28,2^{\circ}-$ y que también indicamos en la Fig. 9.

El análisis del amplio horizonte que se divisa desde el túmulo principal ha proporcionado un número significativo de marcadores astronómicos que pudieron ser utilizados por la comunidad que construyó el túmulo de Peñas Pasera. Como es habitual en este tipo de estudios, hemos centrado nuestra atención principalmente en la búsqueda de orientaciones o

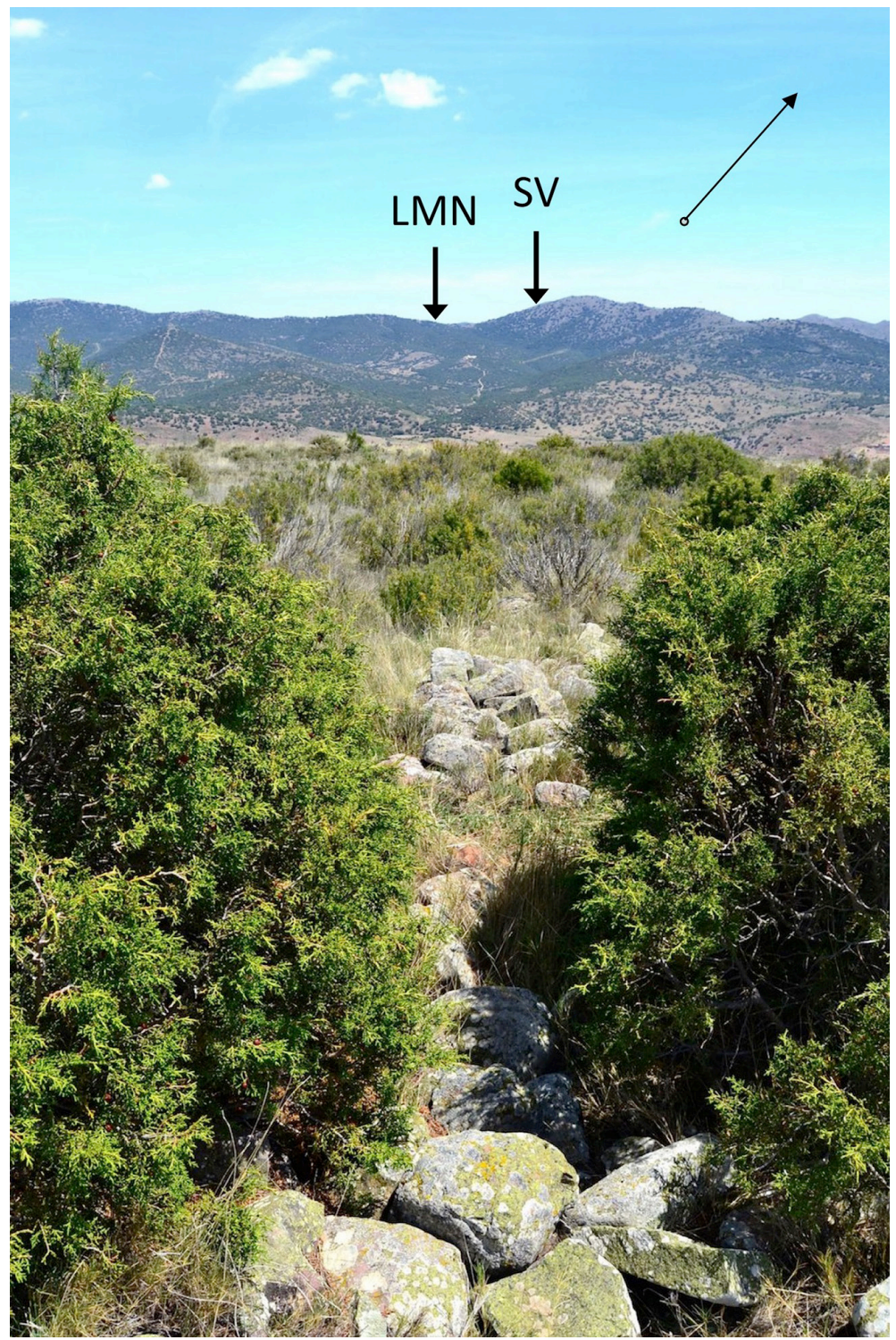

FIG. 9. Vista parcial del horizonte siguiendo el muro de piedras que parte diametralmente el túmulo. Se indican los puntos donde se producian los ortos del Sol en el solsticio de verano (SV) y el de la Luna en el lunasticio mayor norte (LMN) a mediados del primer milenio a. C.; también se indican el tamaño del disco solar (o lunar) y la inclinación de su trayectoria mientras asciende en el cielo; el $N$ se encuentra hacia la izquierda. marcadores de las posiciones extremas del Sol -solsticios- y de la Luna -lunasticios mayores $\mathrm{N}$ y s-, así como del equinoccio o el punto mitad temporal entre solsticios -PMTS-, muy cercano al equinoccio. El pMTs, también conocido como "equinoccio 
megalítico", es un término introducido por Thom en 1967, y corresponde al día que se encuentra justo a mitad del periodo entre los solsticios de verano e invierno. Este día no coincide con los equinoccios debido a que la órbita de la Tierra no es circular y su velocidad alrededor del Sol no es constante. El PMTs se produce entre uno o dos días después del equinoccio de primavera y antes del equinoccio de otoño. La declinación del Sol en esa fecha es de entre $+0,3^{\circ} \mathrm{y}+1^{\circ}$ (Ruggles, 1997) en el momento del amanecer. Por lo tanto, el PMTs permite dividir el año en cuatro partes iguales que, aunque no coinciden exactamente con las estaciones astronómicas de primavera, verano, otońo e invierno tal y como se definen en la actualidad, se delimitarían de forma muy similar y parece ser un concepto mucho más simple e intuitivo que el de equinoccio. El pMTs se ha constatado como objetivo de marcadores en una fracción importante de santuarios ibéricos del SE peninsular (Esteban, 2016, 2017).

También hemos explorado relaciones con los puntos correspondientes a la posición o declinación solar en los momentos que dividen el año trópico ${ }^{5}$ en ocho periodos de igual duración, medidos entre dos solsticios consecutivos de la misma estación, sea el de verano o el de invierno, periodos que se extenderían por unos 45-46 días ${ }^{6}$. Estas posiciones solares se han considerado debido a que Aratis es un yacimiento adscrito a un pueblo celtibérico y porque fechas cercanas a la mitad de las estaciones astronómicas, aunque consideradas como comienzo de las estaciones célticas, fueron hitos fundamentales del calendario celta (MacNeill, 1962; Guibert de la Vaissière, 2003; Torres y Mejuto, 2010). Según las tradiciones irlandesas o galesas, las celebraciones a principios de noviembre, febrero, mayo y agosto indicaban el comienzo de las estaciones para estas

5 Año trópico es el intervalo de tiempo que el Sol tarda aparentemente en completar una vuelta alrededor de la eclíptica, su duración es de 365,242189 días.

6 Estos puntos fueron propuestos por Thom (1967) como elementos de un calendario solar de los constructores de los megalitos de las Islas Británicas. McCluskey (1989) también los exploró en el contexto de los calendarios célticos de Gran Bretaña e Irlanda. comunidades de raigambre celta, definición que no coincide con la que usamos en la actualidad, basada en consideraciones estrictamente astronómicas (García Quintela y González García, 2017). De estas cuatro fechas, las más importantes eran las de noviembre y mayo, pues marcan el comienzo de las 'macroestaciones' celtas de invierno y de verano, que abarcaban medio año cada una. Dichas cuatro celebraciones se fijaron en las fechas del 1 de noviembre, 1 de febrero, 1 de mayo y 1 de agosto del calendario juliano con la llegada del cristianismo y fueron denominadas respectivamente con los nombres de Samhain, Imbolc, Beltane y Lugnasad en Irlanda. Pero, ¿`cuál era la posición solar que correspondía a cada una de dichas celebraciones? Este es un asunto no resuelto y que podría estar relacionado con el momento en que dichas fiestas pasaron al calendario juliano, algo todavía desconocido (McCluskey, 1989) y que además pudo variar de un área geográfica a otra y depender de otros factores difíciles de precisar, por ejemplo, si las celebraciones celtas originales se fijaban siguiendo un conteo exacto de los días o si, por el contrario, la precisión no era algo esencial y se establecían ateniéndose a criterios no estrictamente astronómicos.

En relación a estas celebraciones célticas de comienzo de estación, hemos intentado comprobar varias hipótesis. En primer lugar, hemos supuesto su coincidencia exacta con los días mitad de estación. Si comenzáramos a contar desde el solsticio de invierno, algo que solo determina el orden en que contamos pero no cambia el esquema, el inicio de la primera y quinta octava parte del año corresponderían a ambos solsticios y los de la tercera y séptima al PMTS $^{7}$ anteriormente definido. Por otra parte, los puntos de inicio de la segunda, cuarta, sexta y última octava parte del año, que designaremos o2, o4, o6 y o8, corresponderían a fechas cercanas al comienzo de los meses de febrero, mayo, agosto y noviembre respectivamente. En la época de aparición de la ciudad de Aratis, alrededor del siglo vi a. C., la declinación solar en o2 y o 8 sería de $-16,1^{\circ}$ y de $+16,8^{\circ}$ en el caso de

Es decir, o1 correspondería al solsticio de invierno y 05 al de verano. 03 y o7 a los dos pMTs que tiene un año trópico. 
O4 y o6 -con una incertidumbre de $\pm 0,2^{\circ}$ en ambos casos-, a partir de los cálculos de Thom (1967). La segunda hipótesis es que la relación de las fechas de las celebraciones celtas con dichos inicios de las octavas partes del ańo fuera solo aproximada, al menos en su momento de trasvase al calendario juliano, por lo que también hemos considerado las posiciones o declinaciones solares correspondientes al primer día de los meses de febrero, mayo, agosto y noviembre según los calendarios gregoriano, por una parte, y según el juliano para la fecha de referencia del 550 a. C. ${ }^{8}$, por otra. Esta segunda suposición, al ser más abierta, ya no proporciona un punto sobre el horizonte, sino una horquilla de posibles valores de una anchura de alrededor de $1,6^{\circ}$ en declinación.

En la Fig. 10 mostramos una tabla con los ortos y ocasos correspondientes a todas las posiciones solares y lunares que hemos considerado y las principales relaciones encontradas en cuanto a la alineación del muro y los marcadores sobre el horizonte. La primera columna indica el evento astronómico, la segunda el tipo de calendario usado en la definición de las fechas de algunos eventos, la tercera la declinación solar correspondiente y la cuarta y quinta indican el grado de verosimilitud de los marcadores hacia los ortos - cuarta columna- o hacia los ocasos -quinta columna-. Consideramos que existe un marcador astronómico sobre el horizonte cuando el valor de la declinación del centro del disco solar o lunar, con una holgura de $0,5^{\circ}$ correspondiente al diámetro promedio de dichos astros, coincide con el pico de una montaña, el centro de una hondonada

8 El 1 de febrero, 1 de mayo, 1 de agosto y 1 de noviembre julianos en el 550 a. C. corresponderían al 6 de febrero, 6 de mayo, 6 de agosto y 6 de noviembre en el calendario gregoriano proléptico, extrapolación del calendario gregoriano actual a fechas anteriores a su introducción oficial, que se produjo en 1582. o la intersección entre dos montañas situadas en diferentes planos. A cada relación se le ha asignado un grado de verosimilitud -de mayor a menor: A, B o C- que nos mide de forma subjetiva lo llamativa o verosímil que parece dicha relación como marcador del evento astronómico. El grado A correspondería a un marcador conspicuo en el contexto del horizonte global, coincidente con un elemento topográfico llamativo y con un tamaño limitado, como, por ejemplo, un pico de montaña. También hemos clasificado como A al marcador correspondiente a la orientación del muro, que, aunque no es extremadamente preciso, se refiere a un elemento artificial construido con aparente intencionalidad hacia un evento astronómico. El grado в correspondería a rasgos relativamente llamativos, como la montaña más elevada, por ejemplo, y/o aislados en la zona del horizonte inmediato dentro de una franja de acimut de unos $\pm 5^{\circ}$ alrededor de dicho punto. El grado c definiría marcadores sobre rasgos topográficos poco llamativos y con una morfología similar a otros cercanos dentro de la franja de acimut de $\pm 5^{\circ}$. Finalmente, cuando en cualquiera de las dos 
últimas columnas aparece un guion (-) significa que no se ha encontrado ninguna relación astronómica que cumpla los criterios anteriores.

Vamos a pasar a describir los posibles marcadores encontrados fijándonos en primer lugar en el horizonte oriental, donde se producen los ortos de los cuerpos celestes. En la Fig. 9 podemos ver que el muro de piedras que parte diametralmente el túmulo principal apunta a una zona aproximadamente intermedia entre el lunasticio mayor norte $-\mathrm{LMN}-\mathrm{y}$ el solsticio de verano -SV-, aunque más cercana a este último. Ambos eventos se producen sobre laderas suaves entre La Atalaya y Alto del Marojal, situadas a unos $5 \mathrm{~km}$ de distancia, sin ningún rasgo significativo. Hacia el sur encontramos la zona de los ortos alrededor de comienzos de mayo o agosto (Fig. 11a); mientras el punto correspondiente a $\mathrm{O}_{4} /$ o6 cae en una zona carente de relieve de la vertiente sur de la Loma del Marojal, conocida como Las Jilgueras, la horquilla definida por el 1 de agosto lo hace sobre una pequeña hondonada. Más interesante parece el rango de ortos del 1 de mayo, que se producen sobre una pequeña cumbre situada tras la Loma del Marojal, en la zona de Los Picarios. Clasificamos estos dos últimos marcadores como de Tipo c.

En la Fig. 11b pasamos al área del orto solar alrededor de los equinoccios, que se produce en las cercanías del cerro de El Chorro, situado justo al este del municipio de Oseja, a unos $7 \mathrm{~km}$. En la

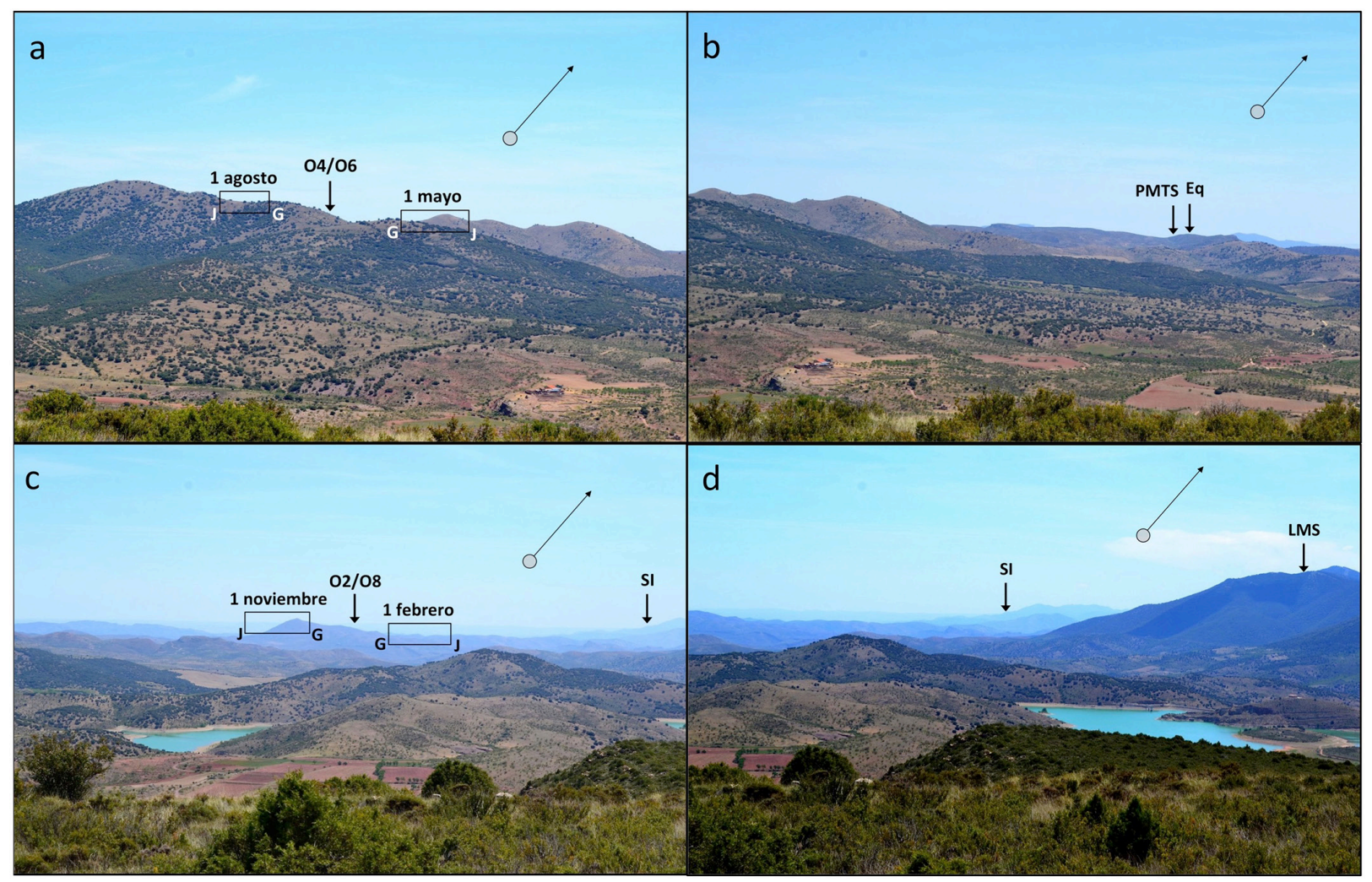

FIG. 11. Vistas parciales del horizonte oriental: a) s la zona donde se producen los ortos alrededor del 1 de mayo o agosto en calendario juliano (J) o gregoriano proléctico (G), también se incluye el punto donde sale el Sol los días del comienzo de la cuarta y sexta octava parte del año (04/06) contando desde el solsticio de invierno; b) puntos del orto solar en el equinoccio y el PMTS; c) ortos correspondientes al 1 de noviembre o febrero y los días del comienzo de la segunda y última octava parte del año (02/O8); d) orto solar en el solsticio de invierno (SI) y el de la Luna en el lunasticio mayor sur (LMS). En todas las imágeness se indica el tamaño del disco solar (o lunar) y la inclinación de su trayectoria mientras asciende en el cielo; el $N$ se encuentra hacia la izquierda. 
posición solar correspondiente al punto medio temporal entre solsticios -PMTs- existe una pequeña hondonada por donde el borde norte del disco solar haría su aparición, mientras que en el equinoccio el Sol aparecería sobre una pequeña y achatada elevación situada al sur de la citada hondonada. Los marcadores del orto del pMTs y del equinoccio también los clasificamos como de Tipo c.

Siguiendo hacia el sur encontramos un marcador más llamativo que los anteriores, ya que el pico triangular de La Lezna, situado en las cercanías de Illueca, a 17,5 km de distancia, coincide de forma muy precisa - menos de $0,1^{\circ}$ de diferencia- con el orto solar del 1 de noviembre gregoriano (Fig. 11c). Consideramos que este es el marcador topográfico más relevante de todos los encontrados, como veremos más adelante -vid. infra-.

El orto del solsticio de invierno se produce sobre la ladera norte de la sierra de Morata, a $29 \mathrm{~km}$ de distancia, en una zona muy interesante ya que corresponde a la intersección de dicha ladera con las montañas más lejanas visibles en esa dirección (Fig. 11d). El orto lunar en el lunasticio mayor sur, el punto más meridional que puede alcanzar la Luna, tiene lugar sobre la ladera norte de la sierra de la Virgen, en un plano más cercano, a unos $11 \mathrm{~km}$ de distancia, aunque sin coincidir con ningún elemento topográfico destacado.

También encontramos marcadores interesantes en la mitad occidental del horizonte, donde se producen los ocasos. En la Fig. 12a vemos que la puesta del Sol en el solsticio de invierno se produce exactamente sobre un cerro de escasa altura que presenta un tamaño angular menor a $1^{\circ}$, posiblemente situado en los alrededores del municipio de Bijuesca, a unos $11 \mathrm{~km}$ de distancia.

Los ocasos del 1 de febrero y o2/o8 se producen sobre los lejanos cerros de Bijuesca (Fig. 12b). El primero de ellos alrededor de una cumbre cónica y relativamente llamativa, aunque no aislada, y el segundo sobre una cumbre plana, por lo que solo consideramos el del 1 de febrero como marcador de grado c. El ocaso del 1 de noviembre se produce sobre la ladera sur de la cercana Peña Molilla, situada a unos $2 \mathrm{~km}$. En la Fig. 12c podemos ver

(c) Universidad de Salamanca que, tanto durante el PMTs o el equinoccio, el borde norte o el sur del disco solar desaparece tras la intersección de la ladera norte de la montańa de la Cucuta, situada a $7,5 \mathrm{~km}$ de distancia, con otras alturas situadas en segundo plano, posiblemente la sierra de la Vigornia, un marcador que clasificamos igualmente como c. Los ocasos del 1 de mayo, O4/ o6 y 1 de agosto se producen en los alrededores de la cumbre del Montalbo, a 6,5 km de distancia (Fig. 12d). El primero de ellos sobre una intersección, el segundo sobre la cumbre principal y el tercero sobre otra intersección de la ladera norte. Los marcadores del ocaso del 1 de mayo y del 1 de agosto los clasificamos como de grado c y el del o4/o6 como A, pues coincide justo con la cumbre de la montaña más elevada de ese sector del horizonte. El ocaso en el solsticio de verano tiene lugar en una zona anodina, sobre la pendiente de la larga y suave ladera norte del Cerro del Pelado, distante 7,8 km (Fig. 12d). Sin embargo, el ocaso lunar en la lunasticio mayor norte se produce muy cerca de la cumbre principal del Cerro del Pelado, un marcador que clasificamos como de grado в ya que el borde norte de la Luna coincidiría justo con dicha intersección.

\subsection{Discusión}

Existen indicios de distinto tipo que inducen a pensar que los pueblos de cultura céltica desarrollaron sistemas de cómputo del tiempo, aunque no parece que existiera un calendario único a nivel global -cf., por ejemplo, García Quintela y González García, 2017-. El descubrimiento del denominado "Calendario de Coligny" en Francia, fechado en el s. II d. C., proporcionó información de primera mano sobre la estructura de estos sistemas, al menos para los celtas continentales (Duval y Pinault, 1986). El elemento más importante de este calendario es su carácter lunisolar, que incluye un sistema para sincronizar el año solar con los meses, que se contaban según las fases lunares $-c f$., por ejemplo, Torres y Mejuto, 2010-. El texto de Coligny indica que el año comenzaba en el mes de Samonios, que se asocia normalmente a la celebración irlandesa de

Zephyrus, LXXXIV, julio-diciembre 2019, 115-137 
Samhain del 1 de noviembre, aunque algunos autores argumentan, dado que samon significa verano en galo (Lambert, 2003), que el comienzo del año coincidía con el solsticio de verano (Le Contel y Verdier, 1997) o incluso con el equinoccio de otońo (Monard, 1999).

En los últimos años han aparecido diversos trabajos arqueoastronómicos que muestran la presencia de orientaciones y marcadores astronómicos en un número cada vez mayor de yacimientos adscritos a la cultura celta o celtibérica de la Península Ibérica. Belmonte y Hoskin (2002) encontraron que las esculturas de verracos de los Toros de Guisando en El Tiemblo, Ávila, están orientadas mirando hacia el ocaso en los equinoccios, aunque Pérez Gutiérrez (2015) muestra que, desde su emplazamiento, el ocaso solar en el solsticio de verano y el lunar en el lunasticio mayor norte se producen sobre la cumbre de la montaña que se encuentra enfrente del monumento. Este mismo autor señala que otra escultura de verraco, localizada en la puerta de San Vicente de la muralla de Ávila, también se encuentra orientada hacia la salida del Sol en el equinoccio. El impresionante santuario rupestre vetón de Ulaca, en Solosancho, provincia de Ávila, muestra diversas orientaciones interesantes, entre las que destacan el solsticio de invierno y el Sol en los alrededores del 1 de noviembre (Pérez Gutiérrez, 2010). Resultados similares parecen darse en las alineaciones definidas entre varias estelas y otros elementos constructivos de la necrópolis de la Osera en Chamartín, Ávila (Pérez Gutiérrez, 2009). En zonas más orientales de la Celtiberia se encuentran marcadores que señalan el ocaso del equinoccio y el solsticio de verano sobre montañas del horizonte local de la plataforma de Segeda, en Mara, Zaragoza (Burillo et al., 2009).

Marcadores y orientaciones hacia el orto solar en el solsticio de invierno y el orto lunar en el lunasticio mayor sur son elementos cada vez más habituales en yacimientos célticos, tal y como constatan, por ejemplo, González García et al. (2016) en las estaciones de grabados rupestres de Laxe dos Carballos, Rotea y Laxe das Cruces en Galicia; el santuario de Panoias en Portugal, y el santuario rupestre de Peñalba de Villastar en Teruel. García y González

(C) Universidad de Salamanca
García (2017) proponen que las comunidades célticas desarrollaron calendarios de horizonte mediante la observación de ortos y ocasos solares y lunares sobre el horizonte local y enumeran la importante cantidad de marcadores hacia la posición del Sol en fechas cercanas a las festividades célticas de comienzo de estación. Estos autores recopilan orientaciones en fechas consistentes dentro de \pm 5 días al 1 de noviembre en el calendario gregoriano proléptico en santuarios o altares rupestres localizados en los castros de Avión y Armea, en Ourense, o en el templo del foro de Veleia, Álava, así como en el mencionado santuario rupestre de Peñalba de Villastar. Por otra parte, el 1 de febrero está presente en la orientación de una grieta en la estación de grabados rupestres de A Ferradura, Ourense, y en la orientación de los edificios públicos romanos más antiguos de la ciudad gala de Lugdunum Conuenarum en Saint Bertrand de Comminges. Desde el santuario rupestre de la cima del importante castro de Baroña en A Coruña, el orto solar del 1 de mayo se produce sobre el Monte Enxa, fecha que también viene marcada por la orientación del foro de la ciudad romana de origen celtíbero de Segobriga. Finalmente, estos autores indican que varios yacimientos franceses, como el santuario del oppidum galo de Corent o la trama urbana de la colonia romana de Lugdunum, muestran orientaciones hacia el 1 de agosto. Otros estudios en necrópolis celtibéricas han permitido observar una cierta intencionalidad astronómica en su construcción, como sucede en La Osera (Martín Escorza y Baquedano, 1998) o El Ceremeño (Cerdeño et al., 2001-2002: 258-260).

Los resultados que obtenemos en el presente trabajo indican la existencia de un gran número de marcadores que pudieron haber sido utilizados en este gran túmulo de Peńas Pasera para establecer un calendario de horizonte, en consonancia con la hipótesis ya comentada de García Quintela y González García (2017) para las comunidades de raigambre céltica. Estos marcadores incluyen posiciones singulares del Sol y la Luna así como las celebraciones de comienzo de estación del mundo celta. Está claro que la naturaleza no se alinea según los intereses humanos y obviamente los marcadores topográficos que

Zephyrus, LXXXIV, julio-diciembre 2019, 115-137 


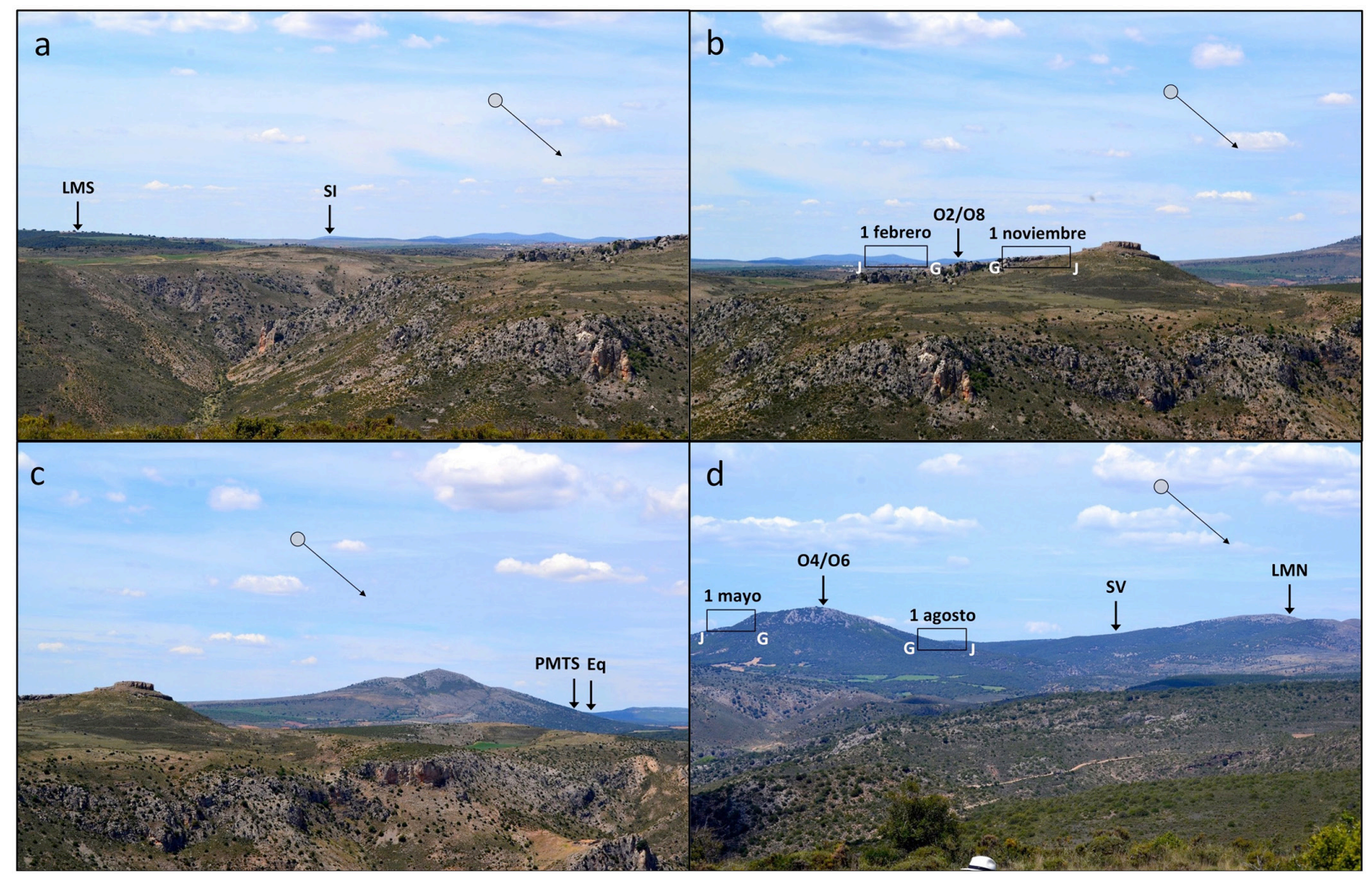

FIG. 12. Vistas parciales del horizonte occidental: a) zona donde se produce el ocaso solar en el solsticio de invierno (SI) y el de la Luna en el lunasticio mayor sur (LMS); b) ocasos correspondientes al 1 de noviembre o febrero y los días del comienzo de la segunda y última octava parte del año (02/O8); c) los puntos del ocaso solar en el equinoccio y el PMTS; d) los ocasos alrededor del 1 de mayo o agosto, el comienzo de la cuarta y sexta octava parte del año (04/o6), el solsticio de verano (SV) y el ocaso de la Luna en el lunasticio mayor norte (LMN). En todas las imágenes se indica el tamaño del disco solar (o lunar) y la inclinación de su trayectoria mientras desciende en el cielo; el $N$ se encuentra hacia la derecha.

mostramos en la tabla de la Fig. 10 y en las Figs. 11 y 12 no pudieron ser construidos ex professo. Tampoco todos tuvieron necesariamente que ser identificados o usados por los constructores de nuestro túmulo. Creemos que al menos algunos de ellos sí que pudieron ser conocidos y que el descubrimiento de su existencia en una fecha indeterminada, siempre posterior al s. vi a. C., pudo ser el motivo de que este gran túmulo, con un claro carácter diferencial, se localizara sobre la cumbre de Peñas Pasera, con una visión espléndida y completa del horizonte, y no en otros lugares de los alrededores.

Según los resultados expuestos en la sección anterior, tenemos bien señalizados los dos puntos extremos de la trayectoria anual solar: los dos solsticios, uno, el de invierno, mediante sendos marcadores tanto al orto como al ocaso y el de verano, que, aunque carece de un marcador topográfico natural, fue señalado mediante la orientación del muro diametral en el túmulo. Todas estas relaciones otorgan una alta probabilidad de que las posiciones extremas del Sol fueran eventos importantes en el ritual de la comunidad que construyó la estructura de Peńas Pasera. Por otra parte, los lunasticios mayores parecen estar indicados por un marcador bastante llamativo -Tipo B- del ocaso del lunasticio mayor norte sobre la cumbre de un monte cercano. Aunque la orientación del muro parece señalar mejor el solsticio de verano, parece muy probable que también quisiera apuntar hacia el lunasticio mayor norte. Por otra parte, nos parece llamativa la ausencia de marcadores hacia el lunasticio mayor sur ya que 
aparece en un número elevado de yacimientos celtas estudiados por otros autores -vid. supra-. Otro evento que está bien señalado, tanto con marcadores al orto como al ocaso, es el equinoccio y/o el PMTs, aunque debido a la pequeña diferencia en declinación de ambos eventos, del orden de un diámetro solar, no nos es posible precisar cuál de los dos eventos podría ser el más importante. De cualquier manera, creemos muy poco probable que el equinoccio astronómico fuera conocido por los antiguos celtíberos de Aratis ya que se trata de un concepto abstracto, que solo tiene sentido práctico cuando se dispone de un modelo geométrico de la esfera celeste, pues se define como uno de los dos momentos del año en que el centro del disco solar cruza el ecuador celeste. De hecho, se cree que fueron astrónomos griegos o babilonios los que descubrieron el concepto del equinoccio entre los ss. IV y II a. C., fechas posteriores a las de la fundación de la ciudad de Aratis.

Las fechas de comienzo de las estaciones celtas, es decir, los primeros días de noviembre, febrero, mayo y agosto, la mitad aproximada de nuestras estaciones astronómicas, muestran marcadores topográficos destacables. El problema con estos eventos es que no corresponden a una declinación precisa, sino a una horquilla de valores de alrededor de $1,6^{\circ}$ de anchura ya que desconocemos el momento en que se trasladaron estas celebraciones al calendario cristiano, por lo que la probabilidad de que el pretendido marcador sea puramente casual es, en principio, más alta para esta serie de eventos.

Entre las fechas de principio de estación destaca la del orto solar del 1 de noviembre, que se produce sobre una cumbre muy destacada del horizonte, el monte de La Lezna, lo que le proporciona un alto grado de relevancia. Según lo que sabemos del calendario celta, esta fecha señalaba el inicio del año y también de la 'macroestación' celta de invierno, que, junto a la de verano que comenzaba el 1 de mayo, dividían el año en dos mitades (Duval y Pinault, 1986: 404-405). Aunque el resto de marcadores asociados a los comienzos de estación celta están clasificados como de tipo c, hay dos que resultan algo más destacables: el del orto del 1 de mayo y el ocaso del 1 de febrero, pues los intervalos de declinación se presentan centrados sobre picos

(C) Universidad de Salamanca relativamente agudos. Finalmente, para los inicios del cuarto de año, eventos que denominamos $\mathrm{O}_{4} /$ o6 y 02/06, solo encontramos un posible marcador, aunque bastante destacable, para el ocaso en el 04/o6, que coincide con la cumbre de un monte cercano (Fig. 12d).

Como vemos, este túmulo pudo haber constituido un lugar privilegiado para hacer seguimiento de un calendario de horizonte a partir de observaciones de ortos y ocasos solares, por lo que el lugar pudo haber tenido un carácter diferencial, incluso sagrado y ceremonial debido a esta conexión entre el paisaje y los astros celestes. Hay varias necrópolis de pueblos de raigambre celta de la Edad del Hierro peninsular que muestran orientaciones astronómicas. Como ya dijimos, Pérez Gutiérrez (2010) encontró alineamientos definidos entre varias estelas y en la estructura conocida como "cuerpo de guardia" hacia el solsticio de invierno y el Sol en los alrededores del 1 de noviembre en la necrópolis vetona de La Osera. Por otra parte, Rodríguez et al. (2006) encuentran que las tumbas de la necrópolis celtibérica de El Ceremeño (Herrería, Guadalajara) parecen orientarse a lo largo de la línea que apunta hacia el orto lunar en el lunasticio mayor norte y el orto solar en el solsticio de verano.

Consideramos de este modo que los resultados arqueoastronómicos obtenidos en el túmulo principal de Peñas Pasera son sólidos, consistentes y similares a los obtenidos en otros yacimientos arqueológicos prerromanos de la Península Ibérica, lo que refuerza la interpretación de que el túmulo estudiado y el resto de estructuras tumulares pertenecieron a la ciudad celtibérica de Aratis.

\section{Conclusiones}

Cada vez resulta más evidente, tal y como hemos podido comprobar, que los pueblos pre- y protohistóricos de la Península Ibérica tenían un conocimiento del medio mucho más profundo del que tradicionalmente se les había supuesto, incluso en campos a priori complejos como puede ser el astronómico; de hecho, los estudios científicos rigurosos que se vienen realizando sobre arqueoastronomía

Zephyrus, LXXXIV, julio-diciembre 2019, 115-137 
en la Península Ibérica no hacen sino comprobar y poner de relieve la estrecha relación entre las estructuras, rituales o no, y los principales hitos astronómicos con ciclos anuales.

Un hecho especialmente relevante dentro del estudio arqueoastronómico del gran túmulo localizado en Peñas Pasera es la orientación del muro que lo corta diametralmente, realizado con plena determinación para ello y que se encuentra orientado con bastante precisión hacia el orto solar del solsticio de verano, un evento fundamental en el mundo celta y para el que no existía un marcador topográfico en el horizonte visible desde ese punto, lo que recalca la voluntad de crear ese hito visual. A este elemento hay que sumar otro muy significativo, la coincidencia precisa del orto solar del 1 de noviembre gregoriano sobre la cima del pico triangular de La Lezna, a $17,5 \mathrm{~km}$ de distancia. Como hemos comentado, esta fecha señalaba el inicio del año celta y de la 'macroestación' de invierno, una fecha que todavía hoy en día está cargada de simbolismo. Creemos que la construcción de este túmulo y los resultados presentados en este trabajo refuerzan, por una parte, la adscripción celtibérica del campo de estructuras tumulares de Peñas Pasera e inciden, por otra, en la ya comentada normalización y aceptación científica de la contemplación y estudio del cielo y los eventos astronómicos por parte de la cultura celtibérica.

Sin entrar a valorar dimensiones que por el momento se nos escapan, como el significado ritual o simbólico, y dejando a un lado la función funeraria o no de los túmulos localizados, algo que deberá ser confirmado taxativamente en su momento por actuaciones arqueológicas específicas, la necesidad de recursos para conocer y determinar con precisión los ciclos anuales está más que justificada en una sociedad como la celtibérica, donde era primordial saber en qué momento del año se encontraban para organizar desde las cosechas hasta las campañas bélicas.

Con un mayor número de estudios arqueoastronómicos rigurosos con seguridad se acabará concluyendo que, lejos de resultar excepcional, estos marcadores e indicadores fueron no solo frecuentes sino imprescindibles. Al parecer, los celtíberos conocían muy bien sus cielos.

(C) Universidad de Salamanca

\section{Bibliografía}

ArLegui, M. (2012): "La necrópolis celtibérica del Inchidero (Aguilar de Montuenga, Soria): estratigrafía, cronotipología y dataciones radiocarbónicas", Complutum, 23 (1), pp. 181-201.

Belmonte, J. A. y Hoskin, M. (2002): Reflejo del Cosmos. Atlas de Arqueoastronomía del Mediterráneo antiguo. Madrid: Equipo Sirius.

Beltrán, A. (1950): Curso de numismática. T. I. Numismática antigua, clásica y de España. Cartagena.

Benavente, J. A.; Fatás, L.; Graells, R. y Melguizo, S. (2012): "Novedades sobre el mundo funerario en el Bajo Aragón (2001-2011)". En Belarte, M. C.; Benavente, J. A.; Fatás, L.; Diloli, J.; Morte, P. y Noguera, J. (eds.): Iberos del Ebro. Actas II Congreso Internacional. Tarragona: ICAC.

Burillo, F.; Pérez Gutiérrez, M. y López Romero, R. (2009): "Estudio arqueoastronómico de la plataforma de Segeda”. En Sáiz, M. E.; López Romero, R.; Cano, M. A. y Calvo, J. C. (eds.): Actas vili Congreso Ibérico de Arqueometría. Teruel: Seminario de Arqueología y Etnología Turolense, pp. 287-294.

Cerdeño, M. L.; Rodríguez, G. y Folgueira, M. (2001-2002): "El paisaje funerario de la Cultura Celtibérica", Anales de Murcia, 16-17, pp. 177-185.

Duval, P. M. y Pinault, G. (1986): Recueil des Inscriptions Gauloises (RIG) sous la direction de Paul-Marie Duval. Vol. 3. Les Calendriers (Coligny, Villards d'Heria). Paris: CNRS.

EGG, M. (2002): "Eisenzeitliche Waffenwihungen im mittleren Alpenraum“. En Kult der Vorzeit in den Alpen: Opfergaben, Opferplätze, Opferbrauchtum, teil 2, pp. 961-984.

Esteban, C. (2016): "Equinoctial Markers in Protohistoric Iberian Sanctuaries", Mediterranean Archaeology and Archaeometry, 16 (4), pp. 297-304.

Esteban, C. (2017): "Lugares de culto y astronomía en Iberia y el Norte de África durante la protohistoria”. En González-García, A. C. y Costa, B. (eds.): XXX Jornadas de arqueología fenicio-púnica (Ibiza, 2015). Ibiza: Museu Arqueològic d'Eivissa i Formentera, pp. 81-116.

Esteban, C. y Moret, S. (2006): "Ciclos de tiempo en la cultura ibérica: la orientación astronómica del Templo del Tossal de Sant Miquel de Llíria", Trabajos de Prehistoria, 63 (1), pp. 167-178.

Faro, J. A. (2015): "La necrópolis del Castillo (Castejón, Navarra): vajilla e instrumental metálico de sacrificio

Zephyrus, LXXXIV, julio-diciembre 2019, 115-137 
y banquete en el valle medio del Ebro (ss. VI-III a. C.)", Lucentum, xxxiv, pp. 31-118.

Fatás, L.; Graells, R.; Lorrio, A. J. y Romeo, F. (2014):

"Dos nuevos cascos hispano-calcídicos en contexto urbano: los oppida celtibéricos de Aratis (Aranda de Moncayo, Zaragoza) y Contrebia Carbica (Villas Viejas, Cuenca)", Boletín del Seminario de Estudios de Arte y Arqueología, Arqueología, lxxx, pp. 13-51.

García Quintela, M. y González García, C. (2017): "Archaeological footprints of the 'Celtic Calendar'?", Journal of Skyscape Archaeology, 3 (1), pp. 49-78.

Gil Farrés, O. (1966): La moneda hispánica en la edad antigua. Madrid: Altamira.

González García, C.; García Quintela, M. y Belmonte, J. A. (2016): "Landscape construction and time reckoning in Iron Age Celtic Iberia", Documenta Praehistorica, XLIII, pp. 479-497.

Graells, R. (2008): La necrópolis protohistórica de Milmanda (Vimbodí, Conca de Barberà, Tarragona). Un exemple del món funerari català durante el trànsit entre els segles VII $i$ VI $a$. C. Tarragona: ICAC.

Graells, R. y Lorrio, A. J. (2013): "El casco celtibérico de Muriel de la Fuente (Soria) y los hallazgos de cascos en las aguas en la Península Ibérica", Complutum, 24 (1), pp. 151-173.

Graells, R.; Lorrio, A. J. y Quesada, F. (2014): Cascos hispano-calcídicos. Simbolo de las élites celtibéricas. Kataloge Vor-und Frühgeschichte, 46. Mainz: RGZM.

Guadán, A. M. de (1980): La moneda ibérica. Cuadernos de Numismática. Madrid.

Guibert de LA VAisssière, V. (2003): Les quatre fêtes d'ouverture de saison de l'Irlande ancienne. Crozon: Éditions Armeline.

LAMBeRT, P. Y. (1997): La Langue gauloise: description linguistique, comentaire d'inscriptions choises. Paris: Errance.

Le Contel, J. M. y Verdier, P. (1997): Un calendrier celtique: le calendrier gaulois de Coligny. Paris: Errance.

Lorrio, A. J. (1997 [2. ${ }^{\text {a }}$ ed. ampliada]): Los celtíberos. Complutum, Extra 7. Bibliotheca Archaeologica Hispana, 25. Madrid: RAH.

Montero, I.; Gómez, P.; Rovira, S. y Lorrio, A. J. (1999): "Minería y metalurgia celtibérica". En BurILlo, F. (coord.): La economía. IV Simposio sobre Celtíberos. Zaragoza: Institución Fernando el Católico, pp. 161-180.

MaCneill, M. (1962): The Festival of Lughnasa: A Study of the Survival of the Celtic Festival of the Beginning of Harvest. Oxford: oup.

Martín Escorza, C. y Baquedano, I. (1998): “Alineaciones astronómicas en la necrópolis de la Edad del
Hierro de La Osera (Chamartín de la Sierra, Ávila)", Complutum, 9, pp. 85-100.

Martínez Naranjo, J. P. y Arenas, J. A. (1999): "La explotación del hierro en el curso alto del río Mesa (Guadalajara) en época celtibérica". En Burillo, F. (coord.): La economía. IV Simposio sobre celtiberos. Zaragoza: Institución Fernando el Católico, pp. 203-208.

Mata, J. M. (1989): "Introducción al estudio de las mineralizaciones del Moncayo y de sus alrededores", Turiaso, IX, pp. 163-174.

McCluskey, J. M. (1989): “The Mid-Quarter Days and the Historical Survival of British Folk Astronomy". Suppl. to the Journal of History of Astronomy, 20. Archaeoastronomy, 13, pp. SI-SI9.

MONARD, J. (1999): Histoire du calendrier gaulois: le calendrier de Coligny. Paris: Burillier.

Pérez Gutiérrez, M. (2009): “Astronomía y geometría en la Vettonia”, Complutum, 20 (2), pp. 141-164 .

Pérez Gutiérrez, M. (2010): Astronomía en los castros celtas de la provincia de Ávila. Ávila: Instit. Gran Duque de Alba.

Pérez Gutiérrez, M. (2015): "Celtic Sites of Central Iberia”. En Ruggles, C. L. N. (ed.): Handbook of Archaeoastronomy and Ethnoastronomy. New York: Springer, pp. 1175-1185.

Polo, C. (1999): "La metalurgia del hierro durante la época celtibérica en Sierra Menera (Guadalajara-Teruel)". En Burillo, F. (coord.): La economía. IV Simposio sobre celtíberos. Zaragoza: Instit. Fernando el Católico, pp. 195-202.

Rodríguez, G.; Sagardoy, T.; Cerdeño, M. L. y FolGUEIRA, M. (2006): "Observaciones topoastronómicas en la Zona Arqueológica de El Ceremeño (Herrería, Guadalajara)", Complutum, 17, pp. 133-144.

Romeo, F. (2002): "Las fortificaciones ibéricas del valle medio del Ebro y el problema de los influjos mediterráneos". En Moret, P. y Quesada, F. (coords.): La guerra en el mundo ibérico y celtibérico (ss. VI-II a. de C.). Madrid: Casa de Velázquez, pp. 153-188.

Romeo, F. (2016): "Conflictos y destrucciones en la Celtiberia Citerior entre los siglos III y I a. C.: el yacimiento de El Calvario, en Gotor, Zaragoza”, Lucentum, xxxv, pp. 65-90.

Romeo, F. (2018): "Contrebia Carbica. Estudio del sistema defensivo para un debate sobre poliorcética y urbanismo en la Celtiberia de los siglos iı y i a. C.”, Complutum, 29 (1), pp. 171-190.

Romeo, F. y Royo, J. I. (2015): "Los sistemas defensivos de los asentamientos y ciudades ibéricas del valle medio del Ebro del siglo III al i a. C. Éxito y olvido de

Zephyrus, LXXXIV, julio-diciembre 2019, 115-137 
un modelo tardío". En Rodríguez Monterrubio, O. (coord.): Fortificaciones en la Edad del Hierro: control de los recursos y el territorio. Valladolid: Glyphos Publicaciones, pp. 341-360.

Ruggles, C. L. N. (1997): "Whose Equinox", Archaeoastronomy, 22 (JHA suppl. xxiII), pp. 45-50.

Tном, A. (1967): Megalithic Sites in Britain. Oxford: oup.
Torres, J. F. y Mejuto, J. (2010): "El 'calendario celta' como fuente para el estudio de la cultura céltica. Arqueoastronomía y etnohistoria”. En Burillo, F. (coord.): Ritos y Mitos. VI Simposio sobre celtiberos. Zaragoza: Centro de Estudios Celtibéricos, pp. 541-551.

Untermann, J. (1975): Monumenta Linguarum Hispanicarum, I. Die Münzlegende. Wiesbaden. 
